Check for updates

Cite this: Phys. Chem. Chem. Phys., 2020, 22, 3620

Received 7th October 2019, Accepted 6th January 2020 DOI: $10.1039 / c 9 c p 05476 f$ rsc.li/pccp

\section{A DFT and KMC based study on the mechanism of the water gas shift reaction on the $\mathrm{Pd}(100)$ surface $\dagger$}

\author{
Arunabhiram Chutia, (D)*ab Adam Thetford, (D) ${ }^{\text {bcd }}$ Michail Stamatakis (D) ${ }^{\mathrm{e}}$ and \\ C. Richard A. Catlow (iD)*bdf
}

\begin{abstract}
We present a combined density functional theory (DFT) and Kinetic Monte Carlo (KMC) study of the water gas shift (WGS) reaction on the $\mathrm{Pd}(100)$ surface. We propose a mechanism comprising both the redox and the associative pathways for the WGS within a single framework, which consists of seven core elementary steps, which in turn involve splitting of a water molecule followed by the production of an $\mathrm{H}$-atom and an $\mathrm{OH}$-species on the $\mathrm{Pd}(100)$ surface. In the following steps, these intermediates then recombine with each other and with $\mathrm{CO}$ leading to the evolution of $\mathrm{CO}_{2}$, and $\mathrm{H}_{2}$. Seven other elementary steps, involving the diffusion and adsorption of the surface intermediate species are also considered for a complete description of the mechanism. The geometrical and electronic properties of each of the reactants, products, and the transition states of the core elementary steps are presented. We also discuss the analysis of Bader charges and spin densities for the reactants, transition states and the products of these elementary steps. Our study indicates that the WGS reaction progresses simultaneously via the direct oxidation and the carboxyl paths on the $\operatorname{Pd}(100)$ surface.
\end{abstract}

\section{Introduction}

The water gas shift (WGS) reaction plays a crucial role in many industrially important processes as diverse as steam-methane reforming for ammonia and methanol synthesis and direct proton exchange membrane fuel cell applications. ${ }^{1-24}$ In the last few years, the mechanism of this reaction has been studied intensively using both theoretical and experimental techniques; it is, however, still extensively debated. ${ }^{25}$ In previous studies, various reaction pathways have been considered; for example, a study by Huang et al. focused on three different pathways for the WGS reaction on the $\mathrm{Fe}_{2} \mathrm{O}_{3}(111)$ surface using density functional theory with Hubbard correction $(\mathrm{DFT}+\mathrm{U})$ i.e. a redox mechanism also known as the regenerative mechanism, the

\footnotetext{
${ }^{a}$ School of Chemistry, Brayford Pool, University of Lincoln, Lincoln, LN6 7TS, UK. E-mail:achutia@lincoln.ac.uk

${ }^{b}$ UK Catalysis Hub, RCaH, Rutherford Appleton Laboratory, Didcot, OX11 OFA, UK

${ }^{c}$ Department of Chemistry, University of Manchester, UK

${ }^{d}$ Department of Chemistry, University College London, Gordon Street, London, WC1H 0AJ, UK. E-mail: c.r.a.catlow@ucl.ac.uk

${ }^{e}$ Department of Chemical Engineering, University College London, Torrington Place, London, WC1E 7JE, UK

${ }^{f}$ Cardiff Catalysis Institute, School of Chemistry, Cardiff University, Cardiff, CF10 3AT, UK

$\dagger$ Electronic supplementary information (ESI) available. See DOI: 10.1039/ c9cp05476f
}

associative or the carboxyl mechanism and the coupling mechanism. ${ }^{3,20}$ In the redox mechanism, the water molecule is dissociated into atomic $\mathrm{H}$ and $\mathrm{O}$ atoms; the dissociated $\mathrm{O}$-atom then interacts with the adsorbed $\mathrm{CO}$ molecule to form $\mathrm{CO}_{2}$. In the associative mechanism, the adsorbed $\mathrm{CO}$ interacts with adsorbed $\mathrm{OH}$ species obtained by partial dissociation of $\mathrm{H}_{2} \mathrm{O}$, to give a carboxyl intermediate, which then decomposes to $\mathrm{CO}_{2}$ and an $\mathrm{H}$-atom. ${ }^{26}$ Finally, in the coupling mechanism, the evolution of $\mathrm{CO}_{2}$ takes place directly from the reaction of $\mathrm{CO}$ and $\mathrm{OH}$ species. This study concluded that the redox mechanism is the most favourable pathway for the WGS reaction on the $\mathrm{Fe}_{3} \mathrm{O}_{4}(111)$ surface. In an earlier work, Gokhale et al. studied all the elementary steps of redox and carboxyl mediated mechanisms for the low-temperature WGS reaction on the $\mathrm{Cu}(111)$ surface, using density functional theory (DFT) and microkinetic modelling. ${ }^{3}$ They proposed that the abstraction of $\mathrm{H}$ from $\mathrm{H}_{2} \mathrm{O}$ is the rate determining step, while in another study Grabow et al. employed DFT, microkinetic modelling and experimental techniques to study the WGS reaction on the Pt(111) surface. ${ }^{18}$ They concluded that formate species act as spectators and cannot be formed from $\mathrm{CO}$ and $\mathrm{OH}$ in a single elementary step. The $\mathrm{CO}$ species was identified as the most abundant of the surface intermediates and the carboxyl group $(\mathrm{COOH})$, formed from $\mathrm{CO}$ and $\mathrm{OH}$, subsequently combined with $\mathrm{OH}$ to form $\mathrm{CO}_{2}$ and $\mathrm{H}_{2} \mathrm{O}$. While this step was considered to be the favoured $\mathrm{CO}_{2}$ formation path, due to its low activation energy 
barrier, their microkinetic modelling study, shows that this reaction is limited by the low $\mathrm{OH}$ coverage. They proposed that the direct decomposition step of $\mathrm{COOH} \rightarrow \mathrm{CO}_{2}+\mathrm{H}$ accounts for $75-95 \%$ of the total $\mathrm{CO}_{2}$ production.

Mohsenzadeh et al. recently reported a DFT based study on the effect of three different Ni surfaces i.e., Ni(111), Ni(110) and $\mathrm{Ni}(100)$ on the WGS reaction. ${ }^{4}$ They considered nine elementary steps, which included water dissociation, CO oxidation and the formation of hydrogen. Their calculations indicated that water dissociation, formyl formation, formate dissociation and formation of $\mathrm{H}_{2}$ have the lowest barrier on the $\mathrm{Ni}(110)$ surface, CO oxidation has the lowest barrier on the $\mathrm{Ni}(100)$ surface. Their analysis showed that the rate limiting step was $\mathrm{CO}+\mathrm{O} \rightarrow \mathrm{CO}_{2}$. The barrier for this reaction decreased in the order of $\mathrm{Ni}(110)>\mathrm{Ni}(111)>\mathrm{Ni}(100)$ surfaces. In another study involving DFT, near-edge X-ray absorption fine structure (NEXAFS) and IR spectroscopy, Senanayake et al. investigated the role of formate, carbonate and carboxyl species as possible intermediates in the WGS reaction on the $\mathrm{Au}(111)$ surface. $^{27}$ They found that for formate, the bidentate is more stable than the monodentate configuration by $\sim 0.650 \mathrm{eV}$ and it is, therefore, unlikely that formate is a key intermediate in the WGS reaction. They concluded that carbonate species are not present during the reaction of $\mathrm{CO}$ with $\mathrm{OH}$ on $\mathrm{Au}(111)$ at 90-120 $\mathrm{K}$ and that carbonate is much less stable on the $\mathrm{Au}(111)$ surface than on oxide surfaces. However, we note that that there are reports where the formate species have been observed as intermediates, for example in studies on the reverse WGS reaction by Choi et al. employing in situ FT-IR and DFT techniques on $\mathrm{Pd}, \mathrm{Ni}, \mathrm{Cu}$ and $\mathrm{Ag} .{ }^{28}$

In addition to pristine metallic surfaces, there are also several reports of investigations of the WGS reaction on metals supported on metal oxides. ${ }^{14,29,30}$ Song et al. for example, employed DFT $+\mathrm{U}$ techniques to understand the mechanism of the WGS reaction on a single $\mathrm{Au}$ atom versus $\mathrm{Au}$ cluster supported on $\mathrm{CeO}_{2} \cdot{ }^{14}$ They concluded that the carboxyl mechanism has a lower energy pathway compared to the redox mechanism. In related studies, the elementary steps involving water splitting, and $\mathrm{CO}$ oxidation have also been studied. For instance, Filhol et al. elucidated the electrochemical activation of water over the $\operatorname{Pd}(111)$ surface and Peterson et al. investigated low temperature $\mathrm{CO}$ oxidation catalysed by atomically dispersed $\mathrm{Pd}$ on $\mathrm{Al}_{2} \mathrm{O}_{3} \cdot{ }^{31,32}$ We also note that the kinetics of the WGS reaction could be also greatly influenced by catalyst supports. For example, earlier studies by Grenoble et al. performed a detailed study on the Group VIIB, VIII and IB metals supported on $\mathrm{Al}_{2} \mathrm{O}_{3}$ and showed that the rate per surface metal atom of Pt supported on $\mathrm{Al}_{2} \mathrm{O}_{3}$ has an higher magnitude as compared to Pt supported on $\mathrm{SiO}_{2}{ }^{33}$

It is clear that despite the wide range of theoretical and experimental studies on the WGS reaction, there are considerable uncertainties regarding the key elementary steps of its reaction mechanism. Therefore, in this study we employ density functional theory (DFT) and Kinetic Monte Carlo (KMC) simulations to understand the mechanism of this important reaction over the $\operatorname{Pd}(100)$ surface.
In this study, we focus our study on the Pd surface as Pd-based membranes are known to be able to isolate hydrogen in large quantities and maintain its stability during the water gas shift reaction. For instance, recent studies have demonstrated that the Pd and Pd-based alloy membranes are able to produce $\mathrm{H}_{2}$ with a high purity of $99.89 \% .^{34,35}$ The choice of the $\operatorname{Pd}(100)$ surface, on the other hand, is largely based on the fact that it is well characterised by a large number of recent experimental studies using in situ methods. ${ }^{36}$ Furthermore, Zhang et al. using periodic DFT showed that the reaction pathways on the $\operatorname{Pd}(111)$ and $\operatorname{Pd}(110)$ surfaces display common features despite the fact that they have different surface symmetries. ${ }^{37}$ Recent, theoretical studies have also shown that the surface energies of the Pd surfaces are in the order $\operatorname{Pd}(111)<\operatorname{Pd}(100)<\operatorname{Pd}(110)$, so the $\operatorname{Pd}(111)$ surface is the most stable surface followed by $\operatorname{Pd}(100)$ and $\operatorname{Pd}(110) .{ }^{28}$ Therefore, we considered the $\operatorname{Pd}(100)$ surface to capture the WGS reaction on the surface, which is experimentally well-known, relatively active but sufficiently stable.

In the following sections, we will present first the details of our computational procedures and a description of the proposed reaction mechanism in terms of geometric and electronic properties, which will be followed by the discussions of the results obtained from the DFT calculations and their implementation in the KMC analysis. We show that the water gas shift reaction progresses simultaneously via both direct oxidation and carboxyl pathways, which consist of seven core elementary steps.

\section{Computational details}

\section{DFT calculations}

We employ the Vienna Ab initio Simulation Package (VASP) to perform DFT calculations. ${ }^{38-41}$ We used the projector augmented wave (PAW) method and the cut-off energy is set to $450 \mathrm{eV}$, which gave bulk energies converged to within $10^{-5} \mathrm{eV}$. We chose a convergence criterion of $0.02 \mathrm{eV}^{-1}$ for our structural optimisations and the Perdew-Wang (PW91) version of the generalized gradient approximation (GGA) to carry out total energy calculations and perform geometry optimisations. ${ }^{42,43}$ We note that the PW91 functional has been shown to be reliable for such studies. ${ }^{44,45}$ For all the calculations an experimental lattice constant of $3.891 \AA$ is used for bulk Pd and the ideal Pd(100) surfaces are modelled by a $3 \times 3$ supercell with 4 atomic layers respectively from bulk Pd. Of the four layers we have relaxed the top two atomic-layers and fixed the bottom two layers to mimic the bulk of the system. Six equivalent layers of vacuum between two successive metal slabs are used. To determine the minimum energy paths for all the elementary steps, we employed the climbing-image nudged elastic band (CI-NEB) method. ${ }^{46,47}$ The transition state of the optimised reaction coordinate was confirmed by calculations of the vibrational frequencies. Since a slab exposes two surfaces (top and the bottom of the slab), placing an adsorbate on one of these generally induces a dipole moment. To eliminate the latter, one can place a second adsorbate symmetrically on the other 
surface; yet, this increases computational cost and leads to problems when calculating transition states (two imaginary frequencies for symmetrically placed transition state species). To avoid these issues, adsorption is allowed on only one of the two surfaces in all of our calculations. The dipole moment for these calculations, due to the adsorbed species is accounted for using the methods according to the works of Makov et al. and Neugebauer et al. $^{48,49}$ as implemented in VASP. A $k$-point grid of $18 \times 18 \times 1$ was used for all the calculations. The adsorption energy of adsorbates on $\operatorname{Pd}(100)$ surface is then calculated using:

$$
E_{\text {ad }}=E_{\text {adsorbate }}+\operatorname{Pd}(100)-\left(E_{\operatorname{Pd}(100)}+E_{\text {adsorbate }}\right),
$$

where, $E_{\text {ad }}$ is the adsorption energy, $E_{\text {adsorbate+Pd(100) }}$ is the energy of the system with the adsorbate on Pd surfaces, $E_{\mathrm{Pd}(100)}$ is the energy of pristine surface and $E_{\text {adsorbate }}$ is the energy of the adsorbate. The adsorption energy values include zero-point energy corrections. The charges on various atoms were obtained using the Bader charge analysis as implemented by Henkelman and co-workers. ${ }^{50}$ It is also worth mentioning that previously, Tsuzuki et al. used PW91 exchange and correlation functional to evaluate nonbonding dispersive interactions, and they found that the interaction energies are very close to their $\operatorname{CCSD}(\mathrm{T})$ and MP2 results. ${ }^{51}$ It has been also reported that PW91 already overestimates the binding energy; therefore, inclusion of additional vdW term does not lead to further improvements. ${ }^{52}$ Further to this, Ortmann et al. also showed that the use of PW91 and PW91 + vdW results in very little difference in lattice parameters, bulk modulus, cohesive energies, vibrational frequencies, bond lengths, of solids and molecules. ${ }^{52}$ Therefore, in this study we have not considered the dispersive effects separately.

\section{Kinetic Monte-Carlo simulations}

The KMC simulations were run using the Zacros code $\mathrm{e}^{53,54}$ (http://zacros.org) with the results processed using MATLAB (https://uk.mathworks.com/). During the simulations, the species number and process statistics were sampled every $1 \mathrm{~ms}$ and a snapshot of the adlayer was taken every $50 \mathrm{~ms}$. We have used $\mathrm{H}_{2} \mathrm{O}, \mathrm{CO}, \mathrm{CO}_{2}$, and the pristine $\mathrm{Pd}(100)$ surface as the reference species. Stiffness scaling was used on all the diffusion and water adsorption and desorption steps to prevent these steps from dominating and hampering time progression past a few milliseconds. All the steps were allowed to be reversible, so that the simulation satisfies microscopic reversibility. It was necessary to include 7 extra steps involving diffusion, adsorption and desorption in the proposed mechanism considered for the DFT calculations, in order to simulate an open system and take into account the mobility of the adsorbates on the surface. The pressure and temperature are kept at 1 atm and $600 \mathrm{~K}$ respectively, which was selected so that a suitable time could be sampled within available computational resources. The partial pressure ratio of $\mathrm{CO}$ and $\mathrm{H}_{2} \mathrm{O}$ was varied, ranging from $1: 1$ to a $1000: 1$ ratio of $\mathrm{CO}$ and $\mathrm{H}_{2} \mathrm{O} .{ }^{55}$ Lateral interactions were calculated by deriving the interaction energies using DFT on two adjacent molecules (both for the same or for different species) on the same surface (see Table S1, ESI $\dagger$ ). ${ }^{56}$ Pre-exponential factors were then computed using the vibrational frequencies from the DFT calculations. A detailed discussion on the evaluation of the pre-exponential factors has been given previously by Stamatakis and co-workers in ref. 57.

\section{Results and discussion}

The overall water gas shift reaction is given by the equation:

$$
\mathrm{CO}+\mathrm{H}_{2} \mathrm{O} \rightleftharpoons \mathrm{CO}_{2}+\mathrm{H}_{2}
$$

To formulate the mechanism of this reaction, we first consider the key intermediates including $\mathrm{H}, \mathrm{O}$, and $\mathrm{OH}$, which can be obtained from $\mathrm{H}_{2} \mathrm{O}$ and the reactant $\mathrm{CO}$, and then determine all the other probable intermediates in this reaction. In a recent study, Mohsenzadeh et al. have shown that HCO is an unstable intermediate; similarly, Plauk et al. have shown that the $\mathrm{OOH}$ intermediate on $\operatorname{Pd}(111)$ and $\operatorname{Pd}(100)$ surfaces will readily dissociate to give $\mathrm{O}$ and $\mathrm{OH}$ intermediates; and as described previously, Grabow et al. reported that the formate species is a spectator species and cannot be formed from $\mathrm{CO}$ and $\mathrm{OH}$ in a single elementary step. ${ }^{4,18,44}$ Therefore, considering all these aspects, we formulated a mechanism consisting of seven core elementary steps involving both redox and carboxyl mechanisms as shown in Fig. 1. We propose that the splitting of the water molecule, gives rise to an adsorbed $\mathrm{H}$-atom and an $\mathrm{OH}$-species on the $\mathrm{Pd}(100)$ surface. In the following steps, these intermediate species combine with CO leading to the evolution of $\mathrm{CO}_{2}$, and $\mathrm{H}_{2}$. We have also considered the possibility that the $\mathrm{CO}_{2}$ molecule is formed via another route involving a carboxyl species. It is worth mentioning that the Boudouard reaction, which is $2 \mathrm{CO} \rightleftharpoons \mathrm{C}_{\text {srf }}+\mathrm{CO}_{2}$, is also one of the probable elementary steps. However, recent studies have shown that the rate of this reaction decreases in presence of $\mathrm{H}_{2} \mathrm{O}$ and $\mathrm{H}_{2} \cdot{ }^{58}$ Additionally, the inclusion of this elementary step could lead to another step i.e., $\mathrm{C}_{\mathrm{srf}} \rightleftharpoons \mathrm{C}_{\mathrm{bulk}}$, as shown by us in our previous studies on palladium carbides, which may greatly affect the mechanism of the water gas shift reaction. ${ }^{59,60}$

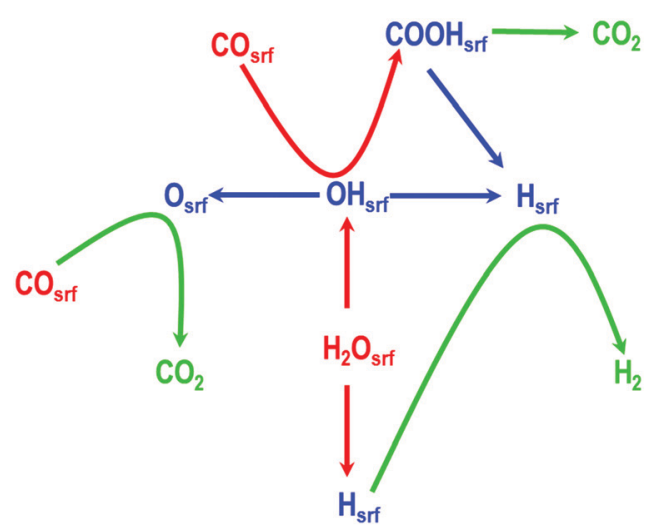

Fig. 1 A mechanism consisting of seven core elementary steps involving both redox and carboxyl mechanisms for water gas shift reaction. For simplicity the adsorption and desorption steps are not shown. 
In this study, to simplify the proposed mechanism we have not included these two steps. For clarity, each of these proposed elementary steps are summarised below (in which the subscript "srf" indicates a surface species):

Step 1: water splitting

$$
\left(\mathrm{H}_{2} \mathrm{O}\right)_{\mathrm{srf}} \rightleftharpoons(\mathrm{OH})_{\mathrm{srf}}+(\mathrm{H})_{\mathrm{srf}}
$$

Step 2: formation of $\mathrm{H}_{2} \mathrm{O}$ and adsorption of $\mathrm{O}$

$$
(\mathrm{OH})_{\mathrm{srf}}+(\mathrm{OH})_{\mathrm{srf}} \rightleftharpoons\left(\mathrm{H}_{2} \mathrm{O}\right)_{\mathrm{srf}}+(\mathrm{O})_{\mathrm{srf}}
$$

Step 3: OH splitting

$$
(\mathrm{OH})_{\mathrm{srf}} \rightleftharpoons(\mathrm{O})_{\mathrm{srf}}+(\mathrm{H})_{\mathrm{srf}}
$$

Step 4: $\mathrm{H}_{2}$ evolution from $(\mathrm{H})_{\text {srf }}$

$$
(\mathrm{H})_{\mathrm{srf}}+(\mathrm{H})_{\mathrm{srf}} \rightleftharpoons \mathrm{H}_{2}
$$

Step 5: CO oxidation

$$
(\mathrm{CO})_{\mathrm{srf}}+(\mathrm{O})_{\mathrm{srf}} \rightleftharpoons \mathrm{CO}_{2}
$$

Step 6: formation of $\mathrm{COOH}$ from $\mathrm{CO}_{\text {srf }}$ and $(\mathrm{OH})_{\mathrm{srf}}$

$$
(\mathrm{CO})_{\mathrm{srf}}+(\mathrm{OH})_{\mathrm{srf}} \rightleftharpoons(\mathrm{COOH})_{\mathrm{srf}}
$$

Step 7: $\mathrm{CO}_{2}$ evolution

$$
(\mathrm{COOH})_{\mathrm{srf}} \rightleftharpoons\left(\mathrm{CO}_{2}\right)_{\mathrm{srf}}+(\mathrm{H})_{\mathrm{srf}}
$$

\begin{tabular}{|c|c|c|c|c|c|}
\hline \multirow[b]{2}{*}{ Species } & \multirow[b]{2}{*}{ Sites } & \multirow{2}{*}{$\begin{array}{l}\text { Proximity } \\
\text { to Pd }\end{array}$} & \multicolumn{2}{|c|}{ Interatomic distances $(\AA)$} & \multirow[b]{2}{*}{$E_{\text {ad }}(\mathrm{eV})$} \\
\hline & & & Pd-A & A-B $(\AA)$ & \\
\hline \multirow[t]{3}{*}{$\mathrm{H}$} & $4 \mathrm{f}$ & $\mathrm{H}$ & 1.981 & - & -2.342 \\
\hline & B & $\mathrm{H}$ & 1.717 & - & -2.342 \\
\hline & $\mathrm{T}$ & $\mathrm{H}$ & 1.555 & - & -1.906 \\
\hline \multirow[t]{3}{*}{$\mathrm{O}$} & $4 \mathrm{f}$ & $\mathrm{O}$ & 2.149 & - & -1.221 \\
\hline & B & $\mathrm{O}$ & 1.933 & - & -0.890 \\
\hline & $\mathrm{T}$ & $\mathrm{O}$ & 1.825 & - & 0.123 \\
\hline \multirow[t]{3}{*}{$\mathrm{CO}$} & $4 \mathrm{f}$ & C & 2.206 & 1.203 & -1.854 \\
\hline & B & C & 2.000 & 1.178 & -1.924 \\
\hline & $\mathrm{T}$ & C & 1.876 & 1.158 & -1.501 \\
\hline \multirow[t]{3}{*}{$\mathrm{OH}$} & $4 \mathrm{f}$ & $\mathrm{O}$ & 2.159 & 0.978 & -3.128 \\
\hline & B & $\mathrm{O}$ & 1.934 & 0.976 & -3.204 \\
\hline & $\mathrm{T}$ & $\mathrm{O}$ & 1.969 & 0.967 & -2.440 \\
\hline \multirow[t]{3}{*}{$\mathrm{CO}_{2}$ (horizontal) } & $4 \mathrm{f}$ & C, O & - & 1.177 & 0.173 \\
\hline & B & $\mathrm{C}, \mathrm{O}$ & - & 1.176 & 0.011 \\
\hline & $\mathrm{T}$ & $\mathrm{C}, \mathrm{O}$ & - & 1.777 & -0.025 \\
\hline \multirow[t]{3}{*}{$\mathrm{H}_{2} \mathrm{O}$} & $4 \mathrm{f}$ & $\mathrm{O}$ & 2.987 & 0.975 & -0.100 \\
\hline & B & $\mathrm{O}$ & 2.484 & 0.973 & -0.147 \\
\hline & $\mathrm{T}$ & $\mathrm{O}$ & 2.966 & 0.980 & -0.076 \\
\hline
\end{tabular}

In addition to these seven core steps, we have also considered the adsorption and desorption of $\mathrm{CO}$ and $\mathrm{H}_{2} \mathrm{O}$

Table 1 The geometry and adsorption energies of various adsorbates with zero point energy corrections on the four-fold hollow (4f), bridge (B) and top $(T)$ sites of $\mathrm{Pd}(100)$ surface. " $A$ " in the table represents the atoms closer to the $\mathrm{Pd}(100)$ surface and diffusion of $\mathrm{CO}, \mathrm{H}_{2} \mathrm{O}, \mathrm{O}, \mathrm{H}, \mathrm{OH}$, and $\mathrm{CO}_{2}$ for a complete description of the WGS reaction, which we will discuss when we present our KMC studies. The geometric and electronic properties of atomic and/or molecular species involved in reactants, products, and transition states of each of these core elementary steps are described in the next section.

\subsection{Adsorption properties of the atomic and molecular species}

We first consider the adsorption energies of all the adsorbed atomic and molecular species on the $\operatorname{Pd}(100)$ surface. The adsorption energies of these species are calculated on top (T) of a Pd atom, in between two Pd atoms i.e. the bridge site (B) and on the four-fold hollow (4f) site. In Table 1, the calculated distances of the atomic and/or molecular species from the $\operatorname{Pd}(100)$ surface, their interatomic distance and the adsorption energies for all these adsorbates are given. The top and side views of all the optimised structures for the atomic and molecular species are also shown in Fig. 2(a-f).

We find that the $\mathrm{H}$-atom displays similar adsorption energies on the four-fold hollow (4f) and the bridge (B) sites
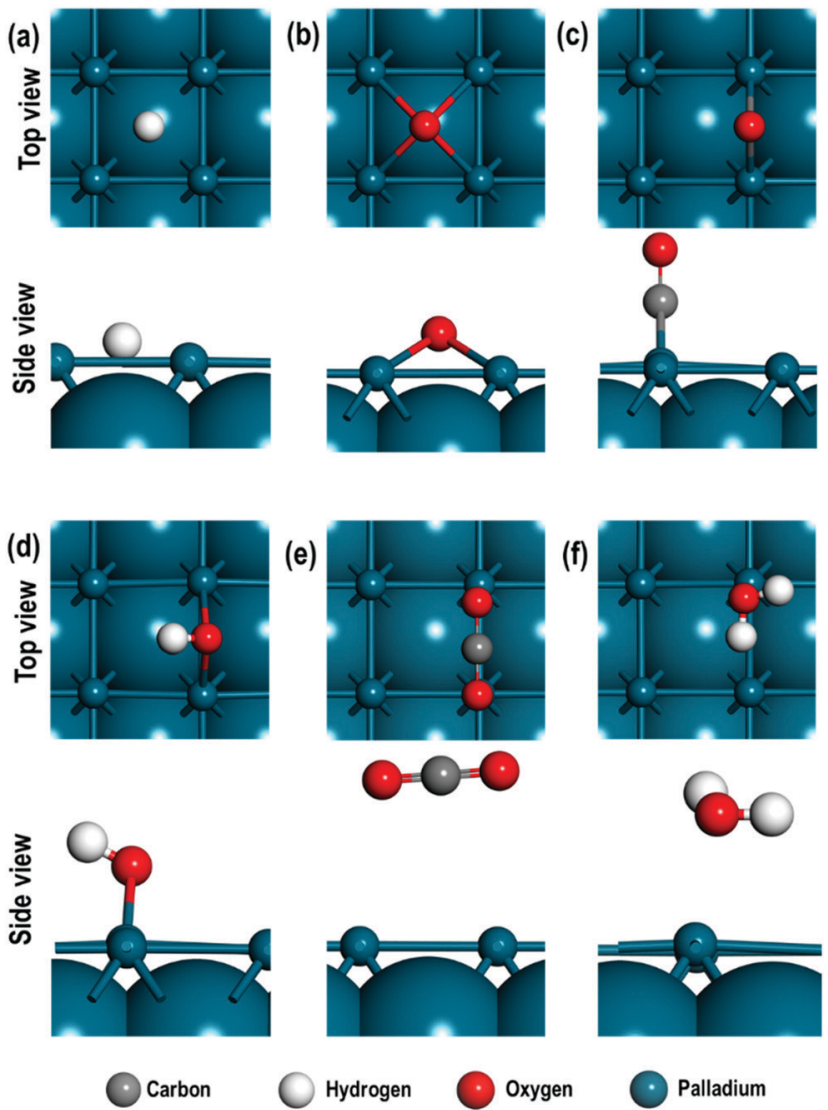

Fig. 2 Top and side views of the most stable structures of (a) $\mathrm{H}$ atom, (b) $\mathrm{O}$ atom, (c) $\mathrm{CO}$ molecule, (d) $\mathrm{OH}$ species, (e) $\mathrm{CO}_{2}$ molecule, and (f) $\mathrm{H}_{2} \mathrm{O}$ molecule. For clarity the uppermost layer is shown as ball and stick format and for the lower subsurfaces van der Waals representation of the atoms is adopted. 
and is stable in both these sites. The adsorption energies of the $\mathrm{O}$-atom indicate strongest binding at the $4 \mathrm{f}$ site. For the diatomic molecules (or species) such as $\mathrm{CO}, \mathrm{OH}$ and $\mathrm{H}_{2}$, we find that the adsorption at the bridge sites is of lower energy. We also note that the adsorbed $\mathrm{OH}$ species display an interesting geometrical property after relaxation i.e., the $\mathrm{H}$ atom adopts a slanted position with respect to the surface Pd-atom to which $\mathrm{O}$ of the $\mathrm{OH}$ species is bound. In contrast, $\mathrm{CO}$ is bound via the $\mathrm{C}$-atom in a perpendicular configuration. The probable reason for this difference can be investigated using Bader charge analysis. The average charge on the Pd atoms on the surface is $0.034 e$ and $0.012 e$ respectively for $\mathrm{OH} / \mathrm{Pd}(100)$ and $\mathrm{CO} / \mathrm{Pd}(100)$ systems. However, when we consider the $\mathrm{Pd}$ atoms in the immediate neighbourhood surrounding the $\mathrm{OH}$ and $\mathrm{CO}$ species, we see that they have a residual average negative charge i.e., -0.020 $e$ and $-0.053 e$ for $\mathrm{OH} / \mathrm{Pd}(100)$ and $\mathrm{CO} / \mathrm{Pd}(100)$ surfaces respectively. On the other hand, the charge on the $\mathrm{H}$-atom of $\mathrm{OH}$ species is $0.595 e$ and $-1.009 e$ for the O-atom in the CO species, resulting in an electrostatic attraction between the $\mathrm{H}$ of $\mathrm{OH}$ species and the $\mathrm{Pd}(100)$ surface and hence the bent structure. The $\mathrm{CO}_{2}$ molecule is weakly adsorbed on the top site, while the $\mathrm{H}_{2} \mathrm{O}$ molecule is weakly chemisorbed on the "bridge-top" site i.e., after relaxation of the
$\mathrm{H}_{2} \mathrm{O}$ molecule adsorbed on the bridge site, it migrates closer to the top site and remains tilted towards the surface.

Having established the favoured sites for the adsorbed species, we now explore their geometrical and electronic properties in more detail.

\subsection{Geometrical and electronic properties of the reactants, and products}

The optimised geometries of all the reactants and the products are reported in Fig. 3(a-f) and summarised in Table 2. Interestingly, the $\mathrm{Pd}-\mathrm{Pd}$ distances in close proximity to the adsorbed sites involving $\mathrm{O}$-atoms are slightly longer than the average values of $2.729 \AA$. For example, in Step 1, the Pd-Pd distance is unperturbed around the adsorbed $\mathrm{H}$-atom but it is $2.884 \AA$ around the $\mathrm{OH}$ species (i.e., longer by $\sim 0.152 \AA$ ). This difference can be attributed to the strong interaction between the O-containing species bound to the neighbouring Pd atoms. To support these conclusions, we analyse the partial density of states (PDOS) of two Pd atoms close to the O-atom (referred to as $\mathrm{Pd}_{1 \text { close }}$ and $\mathrm{Pd}_{2 \text { close}}$ ) and another pair of Pd atoms further away from the O-adsorption site (referred to as $\mathrm{Pd}_{3 \text { far }}$ and $\mathrm{Pd}_{4 \mathrm{far}}$ ). As shown in Fig. 4, the d-orbital signatures completely overlap

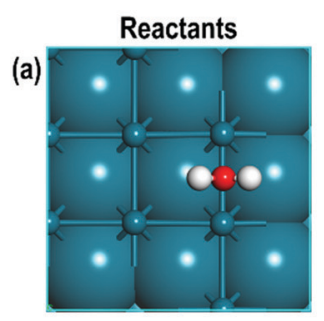

(b)

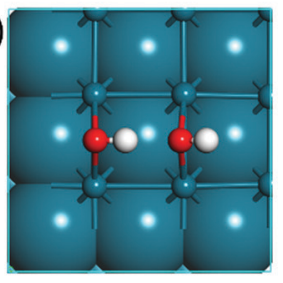

(c)

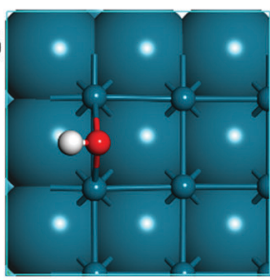

(g)

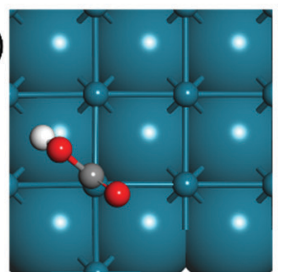

Products
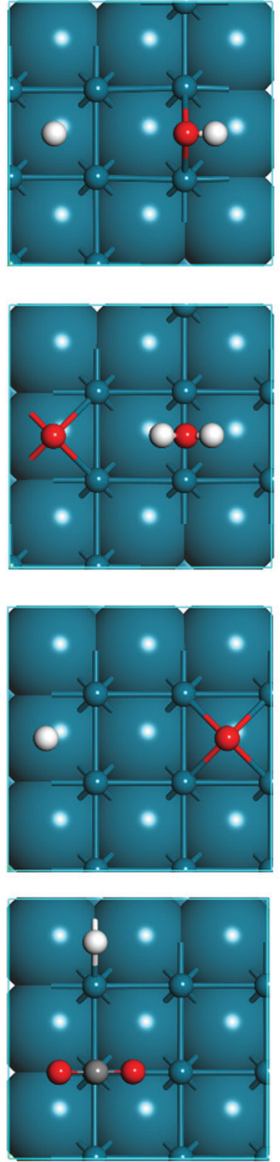

Reactants

(d)

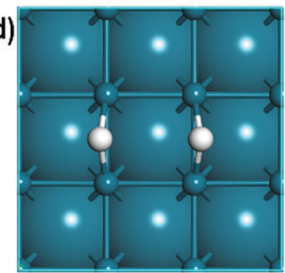

(e)

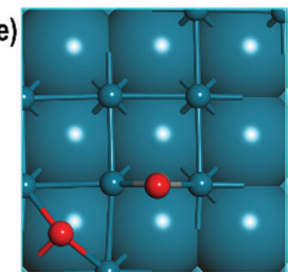

(f)

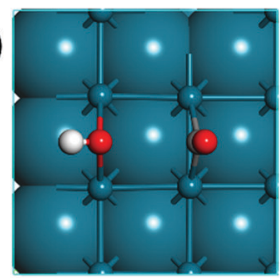

Carbon

Oxygen
Products
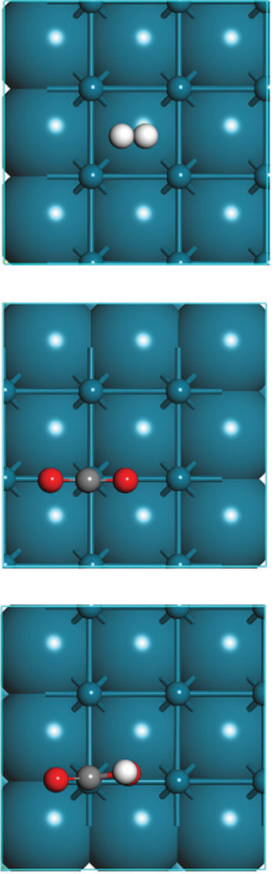

Hydrogen

Palladium

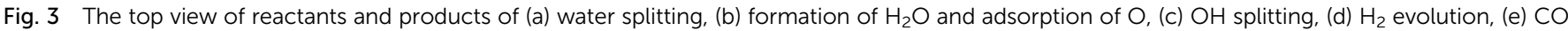

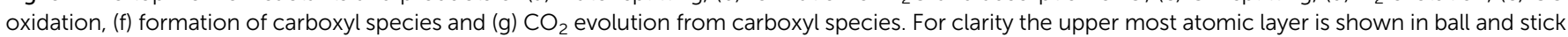
and lower sub-surfaces are shown in van der Waals representation. 
with each other for both pairs of Pd atoms, showing strong d-d interactions. However, despite their similarities we can see that in the former case the intensity of d-orbital signatures around the Fermi energy $\left(E_{\mathrm{F}}\right)$ is lower than with the pair of $\mathrm{Pd}$ atoms further away from the O-adsorption site, implying weakening of $\mathrm{d}-\mathrm{d}$ interactions, which may be related to the polarisation of $\mathrm{Pd}$ atoms due to presence of electronegative $\mathrm{O}$-atom leading to the increased $\mathrm{Pd}-\mathrm{Pd}$ distance. Another interesting point is that, in the former case, we can also see $\mathrm{s}$ and $\mathrm{d}$ signatures at around $-7 \mathrm{eV}$ (Fig. 4(a)), which are missing in the pair of $\mathrm{Pd}$ atoms further away from the O-adsorption site. These additional signatures are due to the interaction of the O-atom with the Pd atoms.

On closely monitoring the Pd-Pd distances for all the reactants and products, we can, however, see an exception to the above observation in step 5 (see Table 2) i.e., in close proximity to an adsorbed O-atom, the $\mathrm{Pd}-\mathrm{Pd}$ distance is $2.778 \AA$, which is similar to the average Pd-Pd distance on the surface. In this case, the adsorbed oxygen atom, in the four-fold hollow site, is shared by four Pd atoms and therefore, the effect of weakening the $\mathrm{d}-\mathrm{d}$ interactions is minimal.

We further analysed the Bader charges of all the reactants and products adsorbed on the $\operatorname{Pd}(100)$ surface, which indicate that the interacting $\mathrm{Pd}\left(\mathrm{Pd}_{\mathrm{int}}\right)$ atoms exhibit mostly positive charges ranging from $0.012 e$ to $0.188 e$, showing that due to the adsorption of various species there is a charge transfer from the Pd surface. In steps 1 , and 4 however, we observe that $\mathrm{Pd}_{\text {int }}$ has zero charge. The analyses of charges show that $\mathrm{O}$-atoms bonded to $\mathrm{H}$ in $\mathrm{OH}, \mathrm{C}$ in $\mathrm{CO}$ or $\mathrm{CO}_{2}$ and $\mathrm{H}$ in $\mathrm{H}_{2} \mathrm{O}$ have charges in the range of $-0.966 e$ to $-1.232 e$ and when they are directly adsorbed on the Pd surface they have a charge of $-0.730 e$. It is interesting to note that the $\mathrm{H}$-atoms are adsorbed on the Pd surface as hydride ions.

\subsection{Geometry, energetics and local electronic properties of the transition states}

In this section, we will describe the geometrical and local electronic properties of the transition states with respect to

Table 2 The $\mathrm{Pd}-\mathrm{Pd}$ on the surface $\left((\mathrm{Pd}-\mathrm{Pd})_{\text {srf }}\right)$ and in proximity $\left((\mathrm{Pd}-\mathrm{Pd})_{\text {near }}\right)$ of the interacting species, the distance between the nearest atom $(\mathrm{A})$ of these species with the $\mathrm{Pd}(100)$ surface and their Bader charges. The coordinates of all the files have been included in the ESI

\begin{tabular}{|c|c|c|c|c|c|c|c|c|c|c|}
\hline \multirow[b]{3}{*}{ Step } & \multirow[b]{3}{*}{ Species on Pd } & \multicolumn{7}{|c|}{ Average interatomic distances $(\AA)$} & \multicolumn{2}{|c|}{$\underline{\text { Bader charges }}$} \\
\hline & & \multirow[b]{2}{*}{$(\mathrm{Pd}-\mathrm{Pd})_{\mathrm{srf}}$} & \multicolumn{2}{|c|}{$(\mathrm{Pd}-\mathrm{Pd})_{\text {near }}$} & \multicolumn{2}{|l|}{$\underline{\mathrm{Pd}-\mathrm{A}}$} & \multirow[b]{2}{*}{$\mathrm{Pd}_{\text {int }}$} & & \multirow[b]{2}{*}{ Species } & \\
\hline & & & Distance & Pd close to & Distance & Pd - species & & & & \\
\hline \multirow[t]{3}{*}{1} & $\mathrm{H}_{2} \mathrm{O}$ & 2.749 & 2.816 & $\mathrm{O}$ of $\mathrm{H}_{2} \mathrm{O}$ & 2.591 & $\mathrm{O}$ of $\mathrm{H}_{2} \mathrm{O}$ & -0.001 & $\mathrm{Pd}_{\mathrm{H}_{2} \mathrm{O}}$ & $\begin{array}{r}-1.232 \\
0.635\end{array}$ & $\begin{array}{l}\mathrm{O} \text { of } \mathrm{H}_{2} \mathrm{O} \\
\mathrm{H} \text { of } \mathrm{H}_{2} \mathrm{O}\end{array}$ \\
\hline & $\mathrm{H}+\mathrm{OH}$ & 2.750 & 2.729 & $\mathrm{H}$ & 1.978 & $\mathrm{H}$ & 0.159 & $\mathrm{Pd}_{\mathrm{OH}}$ & $\begin{array}{r}-1.052 \\
0.651\end{array}$ & $\begin{array}{l}\mathrm{O} \text { of } \mathrm{OH} \\
\mathrm{H} \text { of } \mathrm{OH}\end{array}$ \\
\hline & & & 2.884 & $\mathrm{O}$ of $\mathrm{OH}$ & 2.101 & $\mathrm{O}$ of $\mathrm{OH}$ & 0.045 & $\mathrm{Pd}_{\mathrm{H}}$ & -0.086 & $\mathrm{H}$ \\
\hline \multirow[t]{2}{*}{2} & $\mathrm{OH}+\mathrm{OH}$ & 2.729 & $\begin{array}{l}2.885 \\
2.891\end{array}$ & $\begin{array}{l}\mathrm{O} \text { of } \mathrm{OH} \\
\mathrm{O} \text { of } \mathrm{OH}\end{array}$ & $\begin{array}{l}2.082 \\
2.135\end{array}$ & $\begin{array}{l}\mathrm{O} \text { of } \mathrm{OH} \\
\mathrm{O} \text { of } \mathrm{OH}\end{array}$ & 0.185 & $\mathrm{Pd}_{\mathrm{OH}}$ & $\begin{array}{r}-1.045 \\
0.635\end{array}$ & $\begin{array}{l}\mathrm{O} \text { of } \mathrm{OH} \\
\mathrm{H} \text { of } \mathrm{H}\end{array}$ \\
\hline & $\mathrm{O}+\mathrm{H}_{2} \mathrm{O}$ & 2.754 & $\begin{array}{l}2.763 \\
2.804\end{array}$ & $\begin{array}{l}\mathrm{O} \\
\mathrm{O} \text { of } \mathrm{H}_{2} \mathrm{O}\end{array}$ & $\begin{array}{l}2.154 \\
2.613\end{array}$ & $\begin{array}{l}\mathrm{O} \\
\mathrm{O} \text { of } \mathrm{H}_{2} \mathrm{O}\end{array}$ & $\begin{array}{l}0.087 \\
0.095\end{array}$ & $\begin{array}{l}\mathrm{Pd}_{\mathrm{H}_{2} \mathrm{O}} \\
\mathrm{Pd}_{\mathrm{O}}\end{array}$ & $\begin{array}{r}-1.266 \\
0.654 \\
-0.760\end{array}$ & $\begin{array}{l}\mathrm{O} \text { of } \mathrm{H}_{2} \mathrm{O} \\
\mathrm{H} \text { of } \mathrm{H}_{2} \mathrm{O} \\
\mathrm{O}\end{array}$ \\
\hline \multirow[t]{2}{*}{3} & $\mathrm{OH}$ & 2.754 & 2.877 & $\mathrm{O}$ of $\mathrm{OH}$ & 2.104 & $\mathrm{O}$ of $\mathrm{OH}$ & 0.168 & $\mathrm{Pd}_{\mathrm{O}}$ & $\begin{array}{r}-1.005 \\
0.594\end{array}$ & $\begin{array}{l}\mathrm{O} \text { of } \mathrm{OH} \\
\mathrm{H} \text { of } \mathrm{OH}\end{array}$ \\
\hline & $\mathrm{O}+\mathrm{H}$ & 2.754 & $\begin{array}{l}2.778 \\
2.760\end{array}$ & $\begin{array}{l}\mathrm{H} \\
\mathrm{O}\end{array}$ & $\begin{array}{l}1.714 \\
2.145\end{array}$ & $\begin{array}{l}\mathrm{H} \\
\mathrm{O}\end{array}$ & $\begin{array}{l}0.167 \\
0.008\end{array}$ & $\begin{array}{l}\mathrm{Pd}_{\mathrm{O}} \\
\mathrm{Pd}_{\mathrm{H}}\end{array}$ & $\begin{array}{l}-0.730 \\
-0.062\end{array}$ & $\begin{array}{l}\mathrm{O} \\
\mathrm{H}\end{array}$ \\
\hline 4 & $\begin{array}{l}\mathrm{H}+\mathrm{H} \\
\mathrm{H}_{2}\end{array}$ & $\begin{array}{l}2.751 \\
2.751\end{array}$ & $\begin{array}{l}2.785 \\
2.785 \\
-\end{array}$ & $\begin{array}{l}\mathrm{H} \\
\mathrm{H} \\
-\end{array}$ & $\begin{array}{l}1.715 \\
1.715 \\
-\end{array}$ & $\begin{array}{l}\mathrm{H} \\
\mathrm{H} \\
-\end{array}$ & $\begin{array}{r}0.020 \\
-0.010 \\
-\end{array}$ & $\begin{array}{l}\mathrm{Pd}_{\mathrm{H}} \\
\mathrm{Pd}_{\mathrm{H}} \\
-\end{array}$ & $\begin{array}{r}-0.086 \\
-0.085 \\
0.027 \\
-0.039\end{array}$ & $\begin{array}{l}\mathrm{H} \\
\mathrm{H} \\
\mathrm{H} \\
\mathrm{H}\end{array}$ \\
\hline \multirow[t]{2}{*}{5} & $\mathrm{CO}_{2}$ & 2.749 & - & - & - & - & - & - & $\begin{array}{r}2.090 \\
-1.068\end{array}$ & $\begin{array}{l}\mathrm{C} \text { of } \mathrm{CO}_{2} \\
\mathrm{O} \text { of } \mathrm{CO}_{2}\end{array}$ \\
\hline & $\mathrm{CO}+\mathrm{O}$ & 2.756 & $\begin{array}{l}2.778 \\
2.747\end{array}$ & $\begin{array}{l}\mathrm{O} \\
\mathrm{C} \text { of } \mathrm{CO}\end{array}$ & $\begin{array}{l}2.168 \\
1.998\end{array}$ & $\begin{array}{l}\mathrm{O} \\
\mathrm{C} \text { of } \mathrm{CO}\end{array}$ & $\begin{array}{l}0.135 \\
0.188\end{array}$ & $\begin{array}{l}\mathrm{Pd}_{\mathrm{CO}} \\
\mathrm{Pd}_{\mathrm{O}}\end{array}$ & $\begin{array}{r}-0.731 \\
-0.976 \\
0.844\end{array}$ & $\begin{array}{l}\mathrm{O} \text { on Pd } \\
\mathrm{O} \text { of } \mathrm{CO} \\
\mathrm{C} \text { of } \mathrm{CO}\end{array}$ \\
\hline \multirow[t]{3}{*}{6} & $-\mathrm{COOH}$ & 2.752 & 2.759 & $\mathrm{C}$ of $-\mathrm{COOH}$ & 1.994 & $\mathrm{C}$ of $-\mathrm{COOH}$ & 0.075 & $\mathrm{Pd}_{\mathrm{C}}$ & $\begin{array}{r}1.407 \\
-1.192 \\
-1.094 \\
0.688\end{array}$ & $\begin{array}{l}\mathrm{C} \text { of }-\mathrm{COOH} \\
\mathrm{O}_{\mathrm{H}} \text { of }-\mathrm{COOH} \\
\mathrm{O} \text { of }-\mathrm{COOH} \\
\mathrm{H} \text { of }-\mathrm{COOH}\end{array}$ \\
\hline & $\mathrm{OH}+\mathrm{CO}$ & 2.756 & 2.884 & $\mathrm{O}$ of $\mathrm{OH}$ & 2.104 & $\mathrm{O}$ of $\mathrm{OH}$ & 0.191 & $\mathrm{Pd}_{\mathrm{OH}}$ & $\begin{array}{r}-1.012 \\
0.629\end{array}$ & $\begin{array}{l}\mathrm{O} \text { of } \mathrm{OH} \\
\mathrm{H} \text { of } \mathrm{OH}\end{array}$ \\
\hline & & & 2.771 & $\mathrm{C}$ of $\mathrm{CO}$ & 2.006 & $\mathrm{C}$ of $\mathrm{CO}$ & 0.069 & $\mathrm{Pd}_{\mathrm{CO}}$ & $\begin{array}{r}0.854 \\
-1.047\end{array}$ & $\begin{array}{l}\mathrm{C} \text { of } \mathrm{CO} \\
\mathrm{O} \text { of } \mathrm{CO}\end{array}$ \\
\hline \multirow[t]{2}{*}{7} & $\mathrm{H}+\mathrm{CO}_{2}$ & 2.747 & - & $\mathrm{CO}_{2}$ & - & $\mathrm{CO}_{2}$ & - & - & $\begin{array}{r}1.970 \\
-1.007\end{array}$ & $\begin{array}{l}\mathrm{C} \text { of } \mathrm{CO}_{2} \\
\mathrm{O} \text { of } \mathrm{CO}_{2}\end{array}$ \\
\hline & & & 2.780 & $\mathrm{H}$ & 1.717 & $\mathrm{H}$ & 0.012 & $\mathrm{Pd}_{\mathrm{H}}$ & -0.087 & $\mathrm{H}$ on $\mathrm{Pd}$ \\
\hline
\end{tabular}


the reactants and products. The side and top views of each of the transition states (TS) for all the steps of the proposed mechanism are shown in Fig. 5.

In the first step, $\left[\mathrm{H}_{2} \mathrm{O} \rightleftharpoons(\mathrm{OH})_{\text {srf }}+(\mathrm{H})_{\text {srf }}\right]$, i.e. water splitting, the energy barrier is $1.320 \mathrm{eV}$ and the reaction is slightly exothermic in nature. Previous high-resolution electron energy loss spectroscopy (HEELS), temperature-programmed desorption (TPD) and time-of-flight (TOF) spectroscopic studies on Pd surface have also revealed reversible water dissociation by forming surface hydroxyl $\left(\mathrm{OH}_{\mathrm{srf}}\right)$ groups and $\mathrm{H}$ atoms adsorbed on the surface. ${ }^{61}$ In the transition state, one of the $\mathrm{H}$-atoms is at a distance of $1.460 \AA$ while the other is at a distance of $0.979 \AA$ from the O-atom, i.e. one of the two $\mathrm{O}-\mathrm{H}$ bonds is stretched (Fig. 5(a)). At this stage, the dissociated $\mathrm{H}$-atom is $\sim 1.852 \AA$ away from the Pd surface. The Bader charges show that it has a charge of $0.165 e$, so it is not very strongly adsorbed to the Pd surface, unlike fully dissociated $\mathrm{H}$-atoms, which are adsorbed as hydride ions. To better understand the charge distribution of the transition state, we compare the spin charge densities of the interacting $\operatorname{Pd}(100)$ surface with the pristine $\operatorname{Pd}(100)$ surface (see Fig. 5). In the pristine $\operatorname{Pd}(100)$ surface, the heights of spin density peaks are uniform and a distortion of these peak heights along with the calculated Bader charges will indicate the nature of the interaction between the TS and $\operatorname{Pd}(100)$ surface. The Pd atoms interacting directly with the $\mathrm{O}$-atom (of -OH species) have a shorter peak height due to the electronegative effect of the O-atom. The Bader charge of these two atoms is +0.124 e, i.e. there is charge transfer from the surface to the $-\mathrm{OH}$ species. The other $\mathrm{Pd}$ atoms interact weakly with the $\mathrm{H}$-atom, which has a charge of $+0.016 e$. There is a small distortion in the shapes of the peaks, which may be due to the polarising effects of the Pd atom interacting with the $-\mathrm{OH}$ species.

In the second step, $\left[(\mathrm{OH})_{\text {srf }}+(\mathrm{OH})_{\text {srf }} \rightleftharpoons\left(\mathrm{H}_{2} \mathrm{O}\right)_{\text {srf }}+(\mathrm{O})_{\text {srf }}\right]$, the $-\mathrm{OH}$ species formed in the first step may recombine via an exothermic reaction to give $\mathrm{H}_{2} \mathrm{O}$ and an adsorbed $\mathrm{O}$-atom, the energy barrier for which is found to be $0.880 \mathrm{eV}$. In the transition state, the abstraction of one of the $\mathrm{H}$-atoms from the $-\mathrm{OH}$ species takes place. The distance of this $\mathrm{H}$-atom from the parent $-\mathrm{OH}$ species is $2.000 \AA$, indicating a weak interaction via a $\mathrm{H}$-bond, and its distance from the other $\mathrm{OH}$ species is $\sim 0.990 \AA$, which is close to the normal O-H bond distance in a water molecule. The Bader charge on the adsorbed $\mathrm{O}$-atom is $-0.755 e$ and the average charge on the interacting $\mathrm{Pd}$ atoms is $+0.202 e$, indicating a strong interaction between them. In contrast, the charge on the Pd atom close to the water molecule is $+0.051 e$ revealing a weak interaction between the water molecule and the $\operatorname{Pd}(100)$ surface, which is also evident in the spin density map shown in Fig. 5c.

In the third step, $\left[(\mathrm{OH})_{\text {srf }} \rightleftharpoons(\mathrm{O})_{\text {srf }}+(\mathrm{H})_{\text {srf }}\right]$, the $-\mathrm{OH}$ obtained from water dissociation (in the first step) can further split to give an adsorbed $\mathrm{O}$-atom and $\mathrm{H}$-atom via an exothermic reaction with an energy barrier of $0.320 \mathrm{eV}$. In the transition state, the $\mathrm{O} \cdots \mathrm{H}$ distance has increased to $1.689 \AA$ from the normal O-H distance of $0.978 \AA$. The O-atom has a charge of $-0.658 e$, and Pd atoms directly interacting with it have an average charge of $+0.121 e$, showing that there is a strong charge transfer effect between the dissociated O-atom and the surface. In contrast, the dissociated $\mathrm{H}$-atom has a charge of $+0.096 e$, confirming it to be in the $\mathrm{H}^{+}$ state. The charge on the nearest $\mathrm{Pd}$ atom is zero. As shown in Fig. 6(d), when we visualise the electron spin densities, we find that the peak heights are smaller for the Pd atoms interacting with the adsorbed O-atom (third column from the left in Fig. 6(d)) as compared with the other Pd atoms. The Pd interacting with $\mathrm{H}^{+}$species also show smaller peak heights, which may be related to the polarizing effects of the Pd atoms directly interacting with the electronegative $\mathrm{O}$-atom.

The fourth step, $\left[(\mathrm{H})_{\text {srf }}+(\mathrm{H})_{\text {srf }} \rightleftharpoons \mathrm{H}_{2}\right]$, involves the evolution of the $\mathrm{H}_{2}$ molecule due to the recombination of the adsorbed $\mathrm{H}$ atoms with an energy barrier of $0.810 \mathrm{eV}$. As shown in Table 2, the adsorbed hydride ions are at a distance of $1.715 \AA$ and in the transition state of this reaction, both the $\mathrm{H}$-atoms are at a distance of approximately $2.748 \AA$ from the nearest Pd atom with an interatomic distance of $0.763 \AA$, which is close to the $\mathrm{H}-\mathrm{H}$ bond length in the $\mathrm{H}_{2}$ molecule (see Fig. 5(d)). The calculation of Bader charges indicates that in the transition state, the $\mathrm{H}$-atoms and the closest $\mathrm{Pd}$ atoms have approximately zero charge (Table 3 ). In the spin charge density contour map, we can, however, observe small charges on these Pd atoms (third column in Fig. 6(e)), which may be due to weak electrostatic interactions between the $\mathrm{H} \cdots \mathrm{H}$ species and the surface.

The oxidation of $\mathrm{CO},\left[(\mathrm{CO})_{\text {srf }}+(\mathrm{O})_{\text {srf }} \rightleftharpoons\left(\mathrm{CO}_{2}\right)_{\text {srf }}\right]$, takes place in the fifth step with an energy barrier of $0.690 \mathrm{eV}$. In the transition state (Fig. 5(e)), the $\mathrm{Pd}-\mathrm{O}$ and $\mathrm{Pd}-\mathrm{CO}$ distances are slightly shorter than the $\mathrm{Pd}-\mathrm{O}$ and $\mathrm{Pd}-\mathrm{CO}$ distances in the reactant (Table 2). The $\mathrm{CO}$ has moved from the bridge site towards the adsorbed $\mathrm{O}$-atom in the TS. The Bader charges show that the $\mathrm{C}$ in $\mathrm{CO}$ in the TS is slightly electropositive as compared to the $\mathrm{CO}$ in the reactant, which makes it more feasible for the adsorbed O-atom to combine with the $\mathrm{C}$ of $\mathrm{CO}$

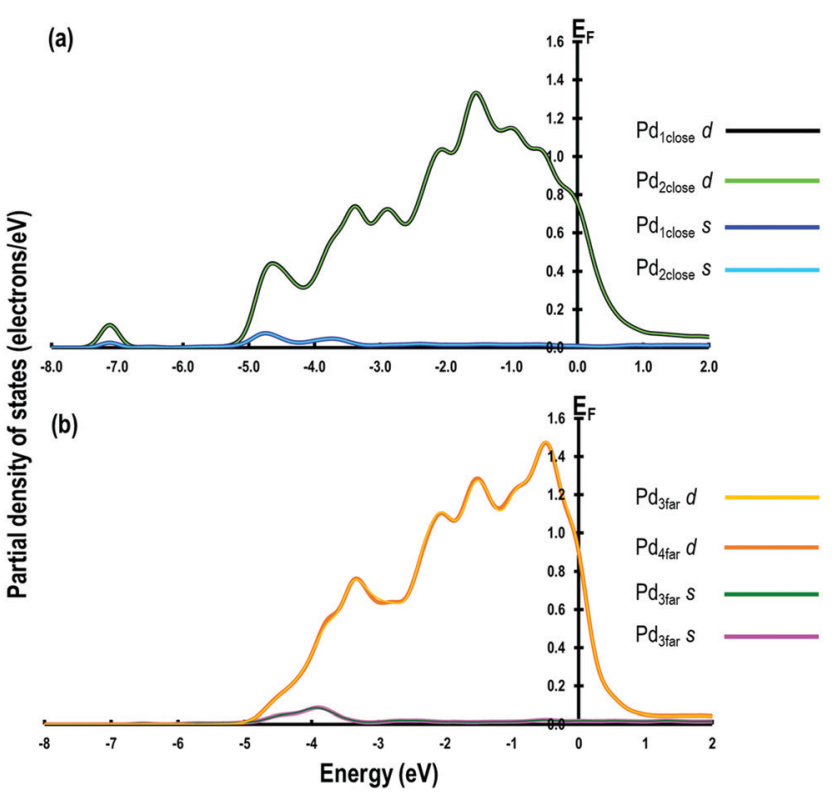

Fig. 4 Partial density of states for (a) Pd atoms in close proximity and (b) $\mathrm{Pd}$ atoms further away from the adsorbed $\mathrm{O}$-atom. 


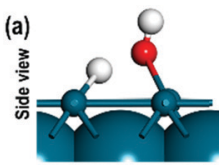

(b)

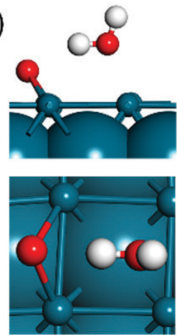

(c)

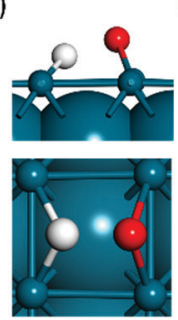

(d)

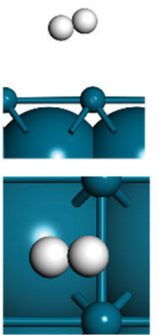

(e)
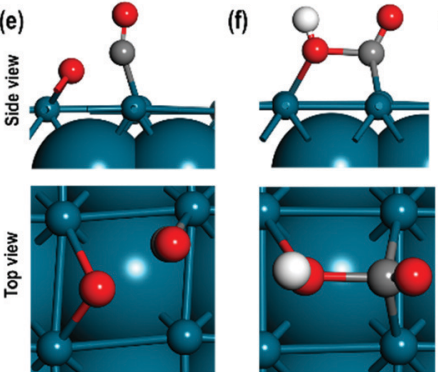

(g)

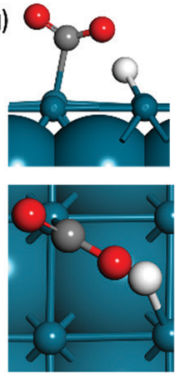

Carbon

Oxygen

Hydrogen

Palladium

Fig. 5 Top and side views of (a) TS1, (b) TS2, (c) TS3, (d) TS4, (e) TS5, (f) TS6, and (g) TS7 where, TS represents transition states and 1-7 represents the steps. For clarity the upper most atomic layer is shown in ball and stick and lower sub-surfaces are shown in van der Waals representation.

to give a $\mathrm{CO}_{2}$ molecule. Furthermore, the charges on the interacting $\mathrm{Pd}$ atoms in the reactants decreased from $+0.188 e$ to $+0.110 e$ indicating that the Pd-CO bond is weak. While in the reactant the $\mathrm{CO}$ is adsorbed to two Pd atoms, in the transition state it is bonded to only one, which is also clearly seen in the charge spin density contour map for the Pd atom directly interacting with the CO (second column third row from the top in Fig. 6(f)).

Previous studies have suggested that bidentate formate is a spectator species in the WGS reaction and hence the energetically less stable carboxyl group, which is adsorbed to the surface through the C-atom, may play a crucial role. ${ }^{18,62}$
Therefore, in addition to the above five steps, we consider two more steps for the WGS reaction, in which the evolution of $\mathrm{CO}_{2}$ molecule may occur via the formation of a carboxyl species due to the reaction between adsorbed $\mathrm{CO}_{\text {srf }}$ with an $\mathrm{OH}$ species, which is step $6\left[(\mathrm{CO})_{\text {srf }}+(\mathrm{OH})_{\text {srf }} \rightleftharpoons(\mathrm{COOH})_{\text {srf }}\right]$. The carboxyl species in step 6 may then decompose to give $\mathrm{CO}_{2}$ and an adsorbed hydrogen atom in step $7\left[(\mathrm{COOH})_{\text {srf }} \rightleftharpoons \mathrm{CO}_{2}+(\mathrm{H})_{\mathrm{srf}}\right]$.

In step 6, the $\mathrm{OH}$ and $\mathrm{CO}$ species are originally bonded to two pairs of nearby Pd surface atoms at a distance of $2.884 \AA$ and $2.771 \AA$ respectively. In the transition state (Fig. 5(f)), the $\mathrm{OH}$ and the $\mathrm{CO}$ species are bonded to only one surface $\mathrm{Pd}$ atom with a distance of $2.078 \AA$ and $2.331 \AA$ respectively and the $\mathrm{O}$ of $\mathrm{OH}$ and $\mathrm{C}$ of $\mathrm{CO}$ are at a distance of $1.669 \AA$. A comparison of the charges in the reactants and the products shows that, during the transition state, the charge on carbon changes from $+0.793 e$ to $+1.053 e$ and the charge on the $\mathrm{O}$-atom of the $\mathrm{OH}$ species changes from $-1.034 e$ to $-1.060 e$, indicating that the $\mathrm{OH}$ species acts as a nucleophile to form a new $\mathrm{C}-\mathrm{O}$ bond to give a carboxyl like species. The charge spin densities show significant changes in the peak heights directly interacting with the $\mathrm{CO}$ and $\mathrm{OH}$ species, which agrees with the calculated charges on these two Pd atoms (see Fig. 6(g) and Table 3). The formation of the carboxyl species is an endothermic reaction with an energy barrier of $0.720 \mathrm{eV}$.

Finally, in step 7, which is an exothermic reaction, the carboxyl species decomposes to give $\mathrm{CO}_{2}$ and a hydrogen atom (hydride ion on the surface) with an energy barrier of $0.540 \mathrm{eV}$ (Table 2). In the transition state (Fig. 5(g)), the $\mathrm{H}$-atom is a distance of $1.465 \AA$, which is longer than the $\mathrm{C}-\mathrm{H}$ distance of $1.109 \AA$ in the carboxyl species indicating that the $\mathrm{H}$-atom is abstracted and has a charge of $+0.208 e$. The Pd atom in the vicinity of the $\mathrm{H}$-atom is almost neutral and in the vicinity of $\mathrm{CO}_{2}$ species, slightly positive $(+0.068 e)$. The charge spin density maps also show that only one Pd atom has a lower peak height

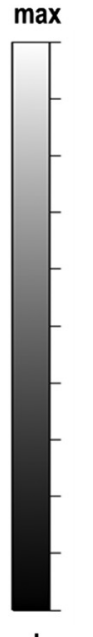

$\min$

(a)

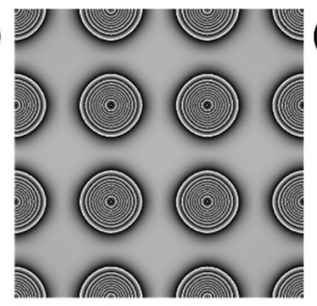

(e)

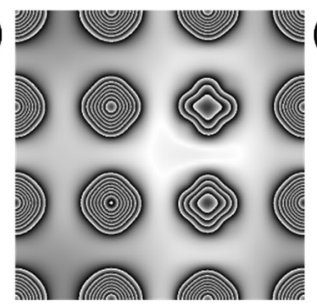

(b)

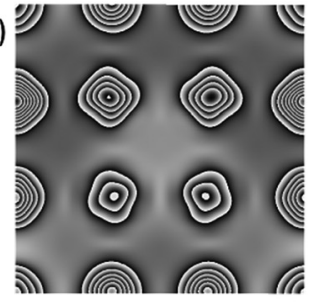

(f)

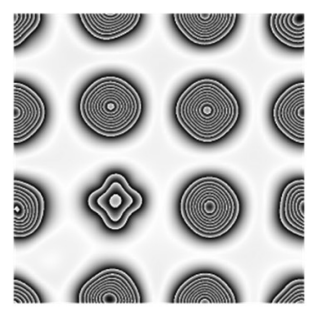

(c)

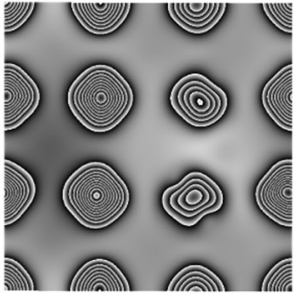

(g)

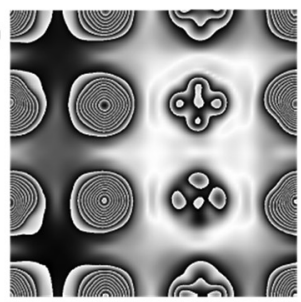

(d)

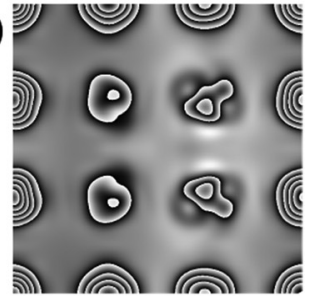

(h)

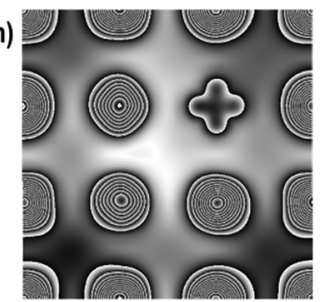

Fig. 6 Spin densities of the exposed surface in (a) pristine $\operatorname{Pd}(100)\left(\min =9.45 \times 10^{-7}\right.$ e $\AA^{-3}$, $\max =4.13 \times 10^{-5}$ e $\left.\AA^{-3}\right)$ and during the interaction of the transition states in (b) step 1 ( $\min =7.63 \times 10^{-7}$ e $\left.\AA^{-3}, \max =2.79 \times 10^{-5} \mathrm{e}^{-3}\right)$, (c) step $2\left(\min =4.44 \times 10^{-7}\right.$ e $\AA^{-3}, \mathrm{max}^{-3} 3.37 \times 10^{-5}$ e $\left.\AA^{-3}\right)$, (d) $\operatorname{step} 3\left(\min =5.52 \times 10^{-8}\right.$ e $\AA^{-3}, \max =1.80 \times 10^{-5}$ e $\left.\AA^{-3}\right)$, (e) step $4\left(\min =-1.68 \times 10^{-7}\right.$ e $\AA^{-3}, \max =2.74 \times 10^{-5}$ e $\left.\AA^{-3}\right)$, (f) step $5(\min =$ $\left.-3.22 \times 10^{-5} \mathrm{e} \AA^{-3}, \max =5.89 \times 10^{-3} \mathrm{e} \AA^{-3}\right),(\mathrm{g}) \operatorname{step} 6\left(\min =-7.71 \times 10^{-8} \mathrm{e} \AA^{-3}, \max =4.69 \times 10^{-6}\right.$ e $\left.\AA^{-3}\right)$ and $(\mathrm{h})$ step $7\left(\min =-3.04 \times 10^{-8}\right.$ e $\AA^{-3}$, $\max =1.02 \times 10^{-5} \mathrm{e}^{-3}$ ). 
Table 3 Interatomic distances and Bader charges for the transition states. The coordinates of all the files have been included in the ESI

\begin{tabular}{|c|c|c|c|c|c|c|c|c|c|}
\hline \multirow{3}{*}{$\frac{\text { TS for step }}{1}$} & \multicolumn{3}{|c|}{ Interatomic distances } & \multicolumn{6}{|c|}{ Bader charges } \\
\hline & \multirow{2}{*}{$\frac{P d-P d_{\text {srf }}}{2.764}$} & \multicolumn{2}{|c|}{ Pd - species } & \multicolumn{2}{|c|}{ Species 1} & \multicolumn{2}{|c|}{ Species 2} & \multirow{2}{*}{$\frac{\mathrm{Pd}_{\text {species } 1}}{0.016}$} & \multirow{2}{*}{$\frac{\mathrm{Pd}_{\text {species } 2}}{0.124}$} \\
\hline & & $\begin{array}{l}1.846 \\
2.200\end{array}$ & $\begin{array}{l}\mathrm{H} \\
\mathrm{O} \text { of } \mathrm{OH}\end{array}$ & 0.165 & $\mathrm{H}$ & $\begin{array}{r}0.585 \\
-1.029\end{array}$ & $\begin{array}{l}\mathrm{H} \text { of } \mathrm{OH} \\
\mathrm{O}\end{array}$ & & \\
\hline 2 & 2.766 & $\begin{array}{l}2.004 \\
2.617\end{array}$ & $\begin{array}{l}\mathrm{O} \\
\mathrm{O} \text { of } \mathrm{H}_{2} \mathrm{O}\end{array}$ & -0.755 & $\mathrm{O}$ & $\begin{array}{r}-1.275 \\
0.654\end{array}$ & $\begin{array}{l}\mathrm{O} \text { of } \mathrm{H}_{2} \mathrm{O} \\
\mathrm{H} \text { of } \mathrm{H}_{2} \mathrm{O}\end{array}$ & 0.202 & 0.051 \\
\hline 3 & 2.765 & $\begin{array}{l}1.766 \\
1.977\end{array}$ & $\begin{array}{l}\mathrm{H} \\
\mathrm{O}\end{array}$ & 0.096 & $\mathrm{H}$ & -0.658 & $\mathrm{O}$ & 0.009 & 0.234 \\
\hline 4 & 2.753 & $\begin{array}{l}2.831 \\
2.816\end{array}$ & $\begin{array}{l}\mathrm{H} \\
\mathrm{H}\end{array}$ & -0.004 & $\mathrm{H}$ & 0.000 & $\mathrm{H}$ & 0.002 & $\begin{array}{l}2 \text { Pd near TS } \\
\text { (negligible charge) }\end{array}$ \\
\hline 5 & 2.743 & $\begin{array}{l}2.035 \\
1.947\end{array}$ & $\begin{array}{l}\mathrm{O} \\
\mathrm{CO}\end{array}$ & -0.710 & $\mathrm{O}$ & $\begin{array}{r}0.999 \\
-1.007\end{array}$ & $\begin{array}{l}\mathrm{C} \text { of } \mathrm{CO} \\
\mathrm{O} \text { of } \mathrm{CO}\end{array}$ & 0.185 & 0.110 \\
\hline 6 & 2.749 & $\begin{array}{l}2.078 \\
2.331\end{array}$ & $\begin{array}{l}\mathrm{C} \text { of } \mathrm{OC}-\mathrm{OH} \\
\mathrm{O} \text { of } \mathrm{HO}-\mathrm{CO}\end{array}$ & $\begin{array}{r}1.053 \\
-1.074\end{array}$ & $\begin{array}{l}\mathrm{C} \text { of } \mathrm{OC}-\mathrm{OH} \\
\mathrm{O} \text { of } \mathrm{OC}-\mathrm{OH}\end{array}$ & $\begin{array}{r}-1.060 \\
0.672\end{array}$ & $\begin{array}{l}\mathrm{O} \text { of } \mathrm{HO}-\mathrm{CO} \\
\mathrm{H} \text { of } \mathrm{HO}-\mathrm{CO}\end{array}$ & 0.097 & 0.113 \\
\hline 7 & 2.755 & $\begin{array}{l}2.057 \\
1.858\end{array}$ & $\begin{array}{l}\mathrm{C} \text { of } \mathrm{COO} \\
\mathrm{H}\end{array}$ & $\begin{array}{r}1.604 \\
-1.008\end{array}$ & $\begin{array}{l}\mathrm{C} \text { of } \mathrm{COO} \\
\mathrm{O} \text { of } \mathrm{COO}\end{array}$ & 0.208 & $\mathrm{H}$ & 0.068 & -0.005 \\
\hline
\end{tabular}

i.e., interacting with the adsorbed $\mathrm{CO}_{2}$ species (Fig. 6(h)). We also note, as shown in Table 3, that for all the transition states, the measured Pd-Pd interatomic distances are close to those in the pristine surface. For clarity the energy barriers for the forward, reverse reactions and the $\Delta E_{\text {reaction }}$ are summarised in Table S2 (ESI $\dagger$ ).

\subsection{Kinetic Monte Carlo simulation}

Using the results of our DFT calculations, we are able to simulate the WGS reaction on $\operatorname{Pd}(100)$ using the Kinetic Monte Carlo (KMC) method, in order to gain deeper insight into the kinetics of the mechanism under reaction conditions. To simulate the reaction mechanism, in addition to the core steps discussed in the previous sections, we consider another seven steps relating to the adsorption, desorption and diffusion of $\mathrm{CO}, \mathrm{CO}_{2}, \mathrm{H}_{2} \mathrm{O}, \mathrm{H}$, and $\mathrm{OH}$. The steps are:

Step 8: CO adsorption

$$
\mathrm{CO}+(*)_{\mathrm{srf}} \rightleftharpoons(\mathrm{CO})_{\mathrm{srf}}
$$

Step 9: $\mathrm{H}_{2} \mathrm{O}$ adsorption

$$
\mathrm{H}_{2} \mathrm{O}+\left({ }^{*}\right)_{\text {srf }} \rightleftharpoons\left(\mathrm{H}_{2} \mathrm{O}\right)_{\text {srf }}
$$

Step 10: O diffusion

$$
(\mathrm{O})_{\mathrm{srf}}+\left({ }^{*}\right)_{\mathrm{srf}} \rightleftharpoons(*)_{\mathrm{srf}}+(\mathrm{O})_{\mathrm{srf}}
$$

Step 11: H diffusion

$$
(\mathrm{H})_{\mathrm{srf}}+\left({ }^{*}\right)_{\mathrm{srf}} \rightleftharpoons(\mathrm{H})_{\mathrm{srf}}+\left({ }^{*}\right)_{\mathrm{srf}}
$$

Step 12: $\mathrm{OH}$ diffusion

$$
(\mathrm{OH})_{\mathrm{srf}}+\left({ }^{*}\right)_{\mathrm{srf}} \rightleftharpoons(*)_{\mathrm{srf}}+(\mathrm{OH})_{\mathrm{srf}}
$$

Step 13: CO diffusion

$$
(\mathrm{CO})_{\mathrm{srf}}+\left({ }^{*}\right)_{\mathrm{srf}} \rightleftharpoons(*)_{\mathrm{srf}}+(\mathrm{CO})_{\mathrm{srf}}
$$

Step 14: $\mathrm{CO}_{2}$ desorption (see step 7)

$$
\left(\mathrm{CO}_{2}\right)_{\mathrm{srf}} \rightleftharpoons \mathrm{CO}_{2}+\left({ }^{*}\right)_{\mathrm{srf}}
$$

For clarity, in the above reactions the surface sites in the diffusion steps are represented by $\left({ }^{*}\right)_{\text {srf }}$. The $\mathrm{CO}$ adsorption, $\mathrm{H}_{2} \mathrm{O}$ adsorption, $\mathrm{O}$ diffusion and $\mathrm{CO}_{2}$ desorption have no energy barriers. The energy barriers for $\mathrm{H}$ diffusion, $\mathrm{OH}$ diffusion and CO diffusions are calculated as $0.017 \mathrm{eV}, 0.400 \mathrm{eV}$ and $0.090 \mathrm{eV}$ respectively, which are obtained from the zeropoint corrected energy of the DFT results.

The KMC simulations show that the coverage of $\mathrm{H}$ is around $0.15 \mathrm{H}$ atoms per site in a monolayer and as shown in Fig. $7(\mathrm{a}$ and $\mathrm{b})$, the coverage of $\mathrm{H}$ exhibited higher fluctuations than that of $\mathrm{CO}$. The $\mathrm{H}$ surface coverage is found to reach values as low as 0.04 and as high as 0.18 (Fig. 7a). The KMC simulations further exhibit an average CO coverage of 0.25 molecules per site (monolayers) (see Fig. 7(b)), which does not change significantly during any of the simulations and was found to be almost constant after the initial adsorption of CO.

(a)

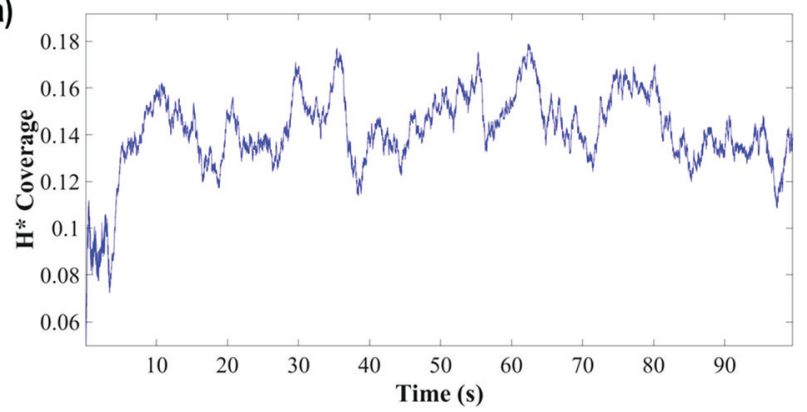

(b)

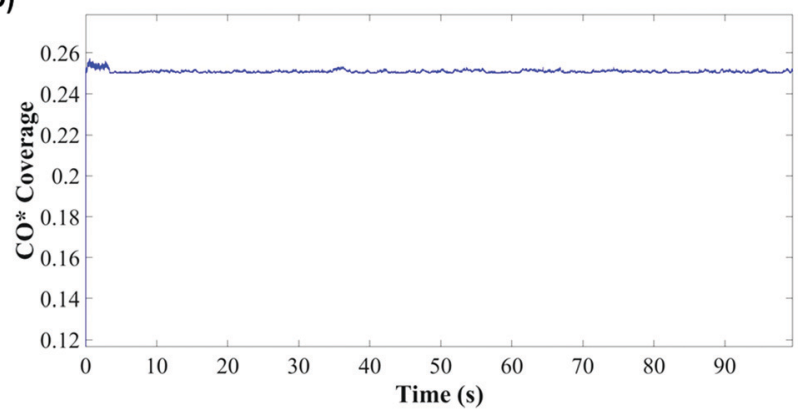

Fig. 7 (a) $\mathrm{H}$ and (b) $\mathrm{CO}$ coverage against time. 
Furthermore, $\mathrm{CO}$ forms patterns on the surface due to lateral interactions, as shown in the snapshots in Fig. $8(\mathrm{a}-\mathrm{c})$.
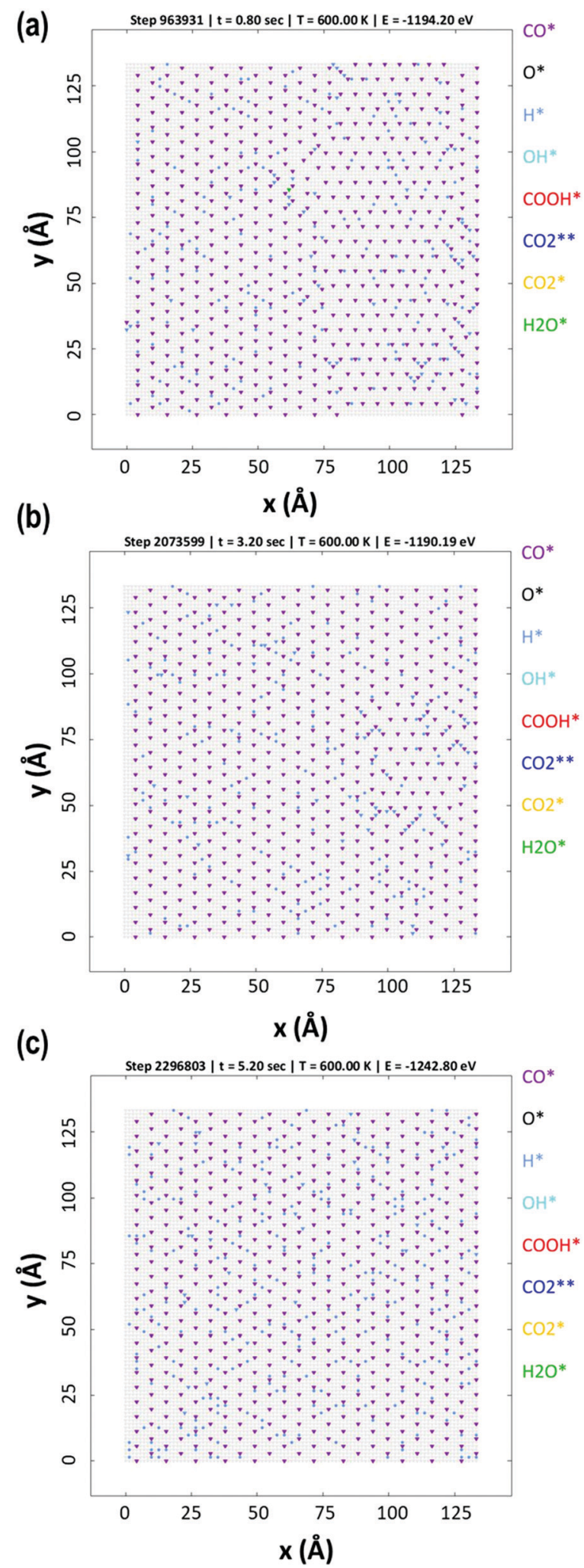

Fig. 8 Snapshots for simulation area at (a) $0.8 \mathrm{~s}$, (b) $3.2 \mathrm{~s}$ and (c) $5.2 \mathrm{~s}$. All simulation have 1 to 1 ratio for $\mathrm{H}_{2} \mathrm{O}$ and $\mathrm{CO}$ in the gas phase, under the conditions stated in computational details section.
Within the first 5 seconds, grain boundaries can be seen between different adsorption patterns, which disappear to form a single adsorption pattern after this time, suggesting an equilibrium period of about $5 \mathrm{~s} .{ }^{63}$ It is also worth noting that only $\mathrm{CO}$ and $\mathrm{H}$ adsorbates are seen on the surface at any of these snapshots meaning that these are the dominant species and under these conditions the turnover for $\mathrm{H}_{2}$ production is found to be low. An increase of the turnover is seen with increasing $\mathrm{H}_{2} \mathrm{O}$ partial pressure, as shown in Fig. 9, with the overall mechanism remaining the same over the whole range.

When the frequencies of the simulated elementary events, shown in Fig. 10, are examined, it is found that adsorption and diffusion events dominate; therefore, these adsorption and diffusion processes are limited ("throttled") by a stiffness scaling method. ${ }^{64-68}$ The other most common events are $\mathrm{H}_{2} \mathrm{O}$ and $\mathrm{OH}$ decomposition, which are also seen to be reversible in nature. The $\mathrm{OH}$ molecule reacts with the CO molecule to form carboxyl which subsequently generates $\mathrm{CO}_{2}$; while the $\mathrm{OH}$ molecule may break down, thereby producing oxygen which then reacts with $\mathrm{CO}$ to form $\mathrm{CO}_{2}$ via direct $\mathrm{CO}$ oxidation. The only other reversible step is the $-\mathrm{COOH}$ formation. Of the remaining 5 steps i.e., 4, 5, 7 and 14 show that the reactions progress only in one direction and step 2 shows no activity. From the above analysis it can be summarised that WGSR mechanism involves both direct oxidation and carboxyl pathways.

\subsection{Summary and conclusions}

Our combined DFT and KMC study of the WGS reaction on the $\operatorname{Pd}(100)$ surface has allowed us to propose a reaction mechanism in which both redox and associative pathways operate within a single framework, which consists of seven core elementary steps. For the complete description of the WGS chemistry, seven additional steps constituting of adsorption, diffusion and desorption are included in the KMC simulations. Our study on the geometrical changes in each of the reactants, products and the transition states shows that irrespective of the type of species adsorbed on the $\operatorname{Pd}(100)$ surface, the average Pd-Pd distance on the surface is always similar except when the adsorbed species are O-atoms. The analysis of electronic properties reveals that this exception is related to the weakening

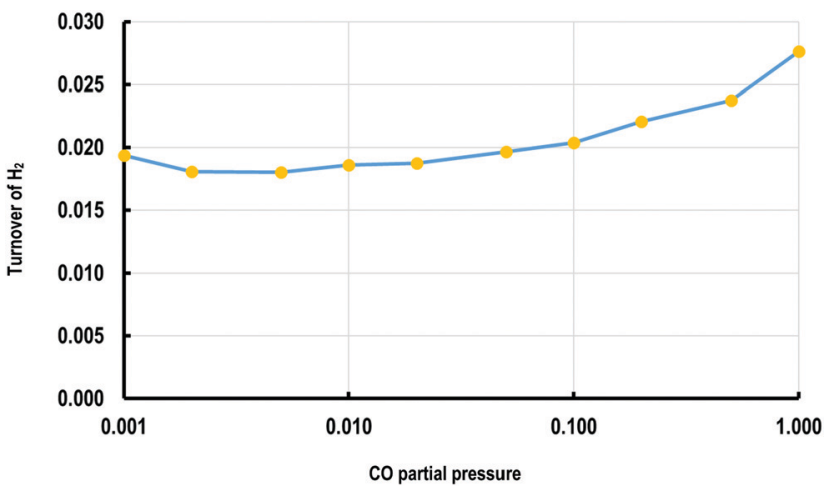

Fig. 9 Plot of turnover frequency for $\mathrm{H}_{2}$ (molecules per site per s) against the ratio of $\mathrm{H}_{2} \mathrm{O} / \mathrm{CO}$ partial pressure (bar). 


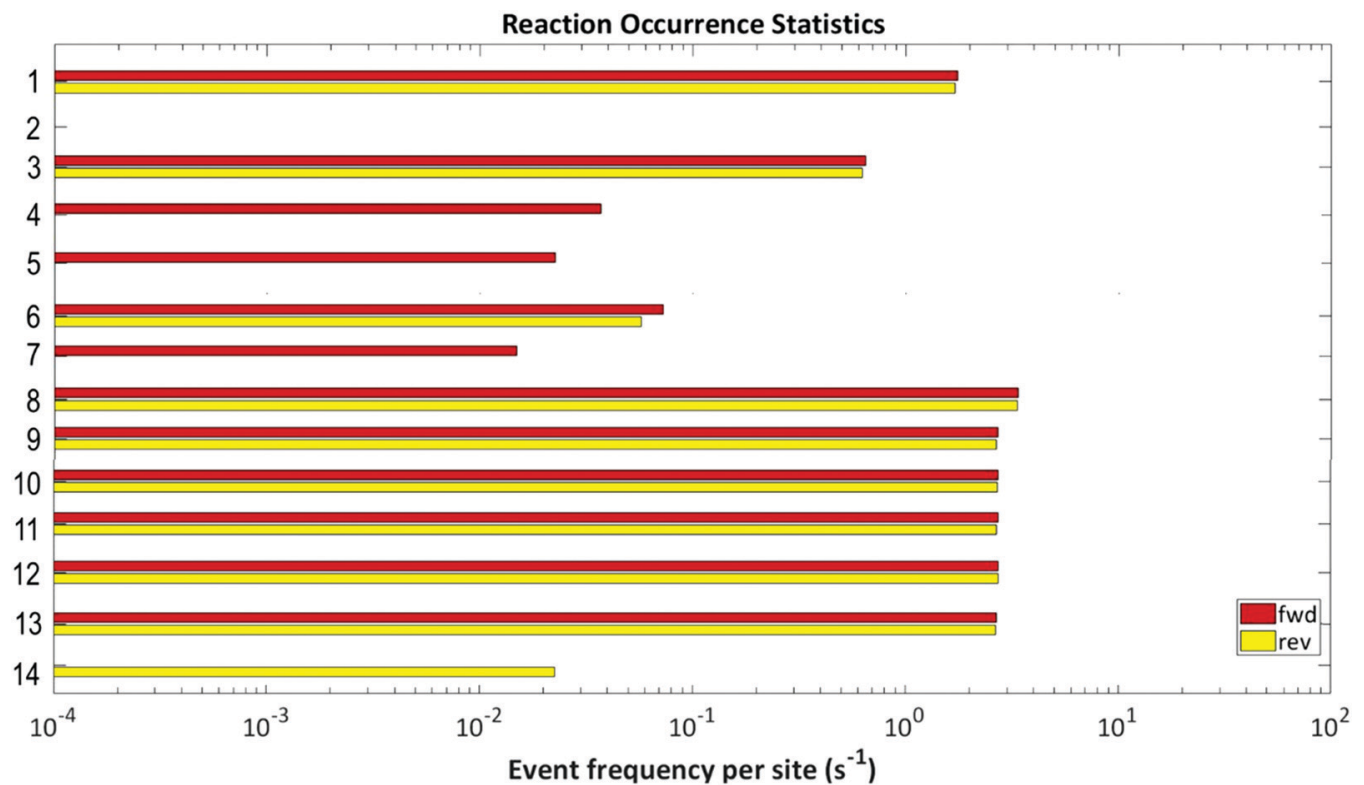

Fig. 10 Event frequency per site for each of the elementary steps of the proposed reaction mechanism.

of $\mathrm{d}$ - $\mathrm{d}$ interactions due to presence of electronegative $\mathrm{O}$-atoms. The calculated energy barriers demonstrate that the splitting of $\mathrm{H}_{2} \mathrm{O}$ to give $\mathrm{OH}$ and $\mathrm{H}$ surface intermediates is the rate determining step. The energy barriers for $\mathrm{OH}$ and $\mathrm{OH}$ recombination to give $\mathrm{H}_{2} \mathrm{O}$ and adsorbed $\mathrm{O}$, and for the hydrogen evolution steps are also high. The KMC study indicates that the $\mathrm{H}_{2} \mathrm{O}$ and $\mathrm{OH}$ decomposition are the most common events i.e., the $\mathrm{OH}$ radical either reacts with the $\mathrm{CO}$ molecule to form carboxyl which subsequently generates $\mathrm{CO}_{2}$; or the radical may break down to oxygen which then reacts with $\mathrm{CO}$ to form $\mathrm{CO}_{2}$ via direct $\mathrm{CO}$ oxidation. From our study we conclude that the redox-associative mechanism of the water gas shift reaction on $\operatorname{Pd}(100)$ progresses via both direct oxidation and carboxyl pathways that occur in parallel, rather than separately, which we consider will lead to a deeper understanding of this important chemical problem on pristine transition metal based catalyst surfaces.

\section{Conflicts of interest}

There are no conflicts to declare.

\section{Acknowledgements}

We thank for resources and support provided via our membership of the UK Catalysis Hub consortium, which is funded by EPSRC (grants EP/K014706/1, EP/K014668/1, EP/K014854/1, EP/ K014714/1, EP/M013219/1). Via our membership of the UK's HEC Materials Chemistry Consortium, which is funded by EPSRC (EP/L000202) this work used the ARCHER UK National Supercomputing Service (http://www.archer.ac.uk). We acknowledge the use of Athena at HPC Midlands+, which was funded by the EPSRC (grant EP/P020232/1), in this research, via the EPSRC RAP call of spring 2018 and 2019. We also thank Supercomputer Wales for the computing time.

\section{References}

1 L. Bollmann, J. L. Ratts, A. M. Joshi, W. D. Williams, J. Pazmino, Y. V. Joshi, J. T. Miller, A. J. Kropf, W. N. Delgass and F. H. Ribeiro, Effect of Zn Addition on the Water-Gas Shift Reaction over Supported Palladium Catalysts, J. Catal., 2008, 257(1), 43-54.

2 T. Bunluesin, R. J. Gorte and G. W. Graham, Studies of the Water-Gas-Shift Reaction on Ceria-Supported Pt, Pd, and Rh: Implications for Oxygen-Storage Properties, Appl. Catal., $B, 1998,15,107-114$.

3 A. A. Gokhale, J. A. Dumesic and M. Mavrikakis, On the Mechanism of Low-Temperature Water Gas Shift Reaction on Copper, J. Am. Chem. Soc., 2008, 130(33), 1402-1414.

4 A. Mohsenzadeh, T. Richards and K. Bolton, DFT Study of the Water Gas Shift Reaction on $\mathrm{Ni}(111), \mathrm{Ni}(100)$ and Ni(110), Surf. Interface Sci., 2016, 644, 53-63.

5 A. A. Phatak, W. N. Delgass, F. H. Ribeiro and W. F. Schneider, Density Functional Theory Comparison of Water Dissociation Steps on Cu, Au, Ni, Pd, and Pt, J. Phys. Chem. C, 2009, 113, 7269-7276.

6 C. Ratnasamy and J. P. Wagner, Water Gas Shift Catalysis, Catal. Rev., 2009, 51(3), 325-440.

7 J. A. Rodriguez, S. D. Senanayake, D. Stacchiola, P. Liu and J. Hrbek, The Activation of Gold and the Water-Gas Shift Reaction: Insights from Studies with Model Catalysts, Acc. Chem. Res., 2014, 47, 773-782.

8 J. A. Rodriguez, P. Liu, J. Hrbek, J. Evans and M. Perez, Water Gas Shift Reaction on $\mathrm{Cu}$ and $\mathrm{Au}$ Nanoparticles Supported on $\mathrm{CeO}_{2}$ (111) and $\mathrm{ZnO}(000 \overline{1})$ : Intrinsic Activity and Importance of Support Interactions, Angew. Chem., Int. Ed., 2007, 119, 1351-1354.

9 J. A. Rodríguez, J. Evans, J. Graciani, J.-B. Park, P. Liu, J. Hrbek and J. F. Sanz, High Water-Gas Shift Activity in $\mathrm{TiO}_{2}$ (110) Supported $\mathrm{Cu}$ and $\mathrm{Au}$ Nanoparticles: Role of the Oxide and Metal Particle Size, J. Phys. Chem. C, 2009, 113(17), 7364-7370. 
10 E. T. Saw, U. Oemar, X. R. Tan, Y. Du, A. Borgna, K. Hidajat and S. Kawi, Bimetallic Ni-Cu Catalyst Supported on $\mathrm{CeO}_{2}$ for High-Temperature Water-Gas Shift Reaction: Methane Suppression via Enhanced CO Adsorption, J. Catal., 2014, 314, 32-46.

11 M. Shekhar, J. Wang, W.-S. Lee, W. D. Williams, S. M. Kim, E. A. Stach, J. T. Miller, W. N. Delgass and F. H. Ribeiro, Size and Support Effects for the Water-Gas Shift Catalysis over Gold Nanoparticles Supported on Model $\mathrm{Al}_{2} \mathrm{O}_{3}$ and $\mathrm{TiO}_{2}$, J. Am. Chem. Soc., 2012, 134(10), 4700-4708.

12 R. Si and M. Flytzani-Stephanopoulos, Shape and CrystalPlane Effects of Nanoscale Ceria on the Activity of $\mathrm{Au}-\mathrm{CeO}_{2}$ Catalysts for the Water-Gas Shift Reaction, Angew. Chem., Int. Ed., 2008, 47(15), 2884-2887.

13 M. Flytzani-Stephanopoulos, Gold Atoms Stabilized on Various Supports Catalyze the Water-Gas Shift Reaction, Acc. Chem. Res., 2014, 47(3), 783-792.

14 W. Song and E. J. M. Hensen, Mechanistic Aspects of the Water-Gas Shift Reaction on Isolated and Clustered Au Atoms on $\mathrm{CeO}_{2}(110)$ : A Density Functional Theory Study, ACS Catal., 2014, 4(6), 1885-1892.

15 M. Stamatakis, Y. Chen and D. G. Vlachos, First-PrinciplesBased Kinetic Monte Carlo Simulation of the Structure Sensitivity of the Water-Gas Shift Reaction on Platinum Surfaces, J. Phys. Chem. C, 2011, 115(50), 24750-24762.

16 A. A. Upadhye, I. Ro, X. Zeng, H. J. Kim, I. Tejedor, M. A. Anderson, J. A. Dumesic and G. W. Huber, PlasmonEnhanced Reverse Water Gas Shift Reaction over Oxide Supported Au Catalysts, Catal. Sci. Technol., 2015, 5(5), 2590-2601.

17 J. Yu, F. J. Tian and C. Z. Li, Novel Water-Gas-Shift Reaction Catalyst from Iron-Loaded Victorian Brown Coal, Energy Fuels, 2007, 21(2), 395-398.

18 L. C. Grabow, A. A. Gokhale, S. T. Evans, J. A. Dumesic and M. Mavrikakis, Mechanism of the Water Gas Shift Reaction on Pt: First Principles, Experiments, and Microkinetic Modeling, J. Phys. Chem. C, 2008, 112(12), 4608-4617.

19 L. Gradisher, B. Dutcher and M. Fan, Catalytic Hydrogen Production from Fossil Fuels via the Water Gas Shift Reaction, Appl. Energy, 2015, 139, 335-349.

20 L. Huang, B. Han, Q. Zhang, M. Fan and H. Cheng, Mechanistic Study on Water Gas Shift Reaction on the $\mathrm{Fe}_{3} \mathrm{O}_{4}$ (111) Reconstructed Surface, J. Phys. Chem. C, 2015, 119(52), 28934-28945.

21 N. Kuriakose, S. Kadam and K. Vanka, A Theoretical Study of Metal-Metal Cooperativity in the Homogeneous Water Gas Shift Reaction, Inorg. Chem., 2012, 51(1), 377-385.

22 J. Lin, A. Wang, B. Qiao, X. Liu, X. Yang, X. Wang, J. Liang, J. Li, J. Liu and T. Zhang, Remarkable Performance of $\operatorname{Ir}_{1} /$ $\mathrm{FeO}_{x}$ Single-Atom Catalyst in Water Gas Shift Reaction, J. Am. Chem. Soc., 2013, 135(41), 15314-15317.

23 C. H. Lin, C. L. Chen and J. H. Wang, Mechanistic Studies of Water-Gas-Shift Reaction on Transition Metals, J. Phys. Chem. C, 2011, 115(38), 18582-18588.

24 A. Herron, J. Scaranto, P. Ferrin, S. Li and M. Mavrikakis, Trends in Formic Acid Decomposition on Model Transition Metal Surfaces: A Density Functional Theory Study, ACS Catal., 2014, 4, 4434-4445.
25 K. Ding, A. Gulec, A. M. Johnson, N. M. Schweitzer, G. D. Stucky, L. D. Marks and P. C. Stair, Identification of Active Sites in CO Oxidation and Water-Gas Shift over Supported Pt Catalysts, Science, 2015, 350(6257), 189-192.

26 E. F. Armstrong and T. P. Hilditch, Interaction of Carbon Monoxide and Steam as Conditioned, Proc. R. Soc. London, Ser. A, 1920, 97(1909), 265-273.

27 S. D. Senanayake, D. Stacchiola, P. Liu, C. B. Mullins and J. Hrbek, Interaction of $\mathrm{CO}$ with $\mathrm{OH}$ on $\mathrm{Au}$ (111): HCOO, $\mathrm{CO}_{3}$, and HOCO as Key Intermediates in the Water-Gas Shift Reaction, J. Phys. Chem. C, 2009, 113(2), 19536-19544.

28 S. Choi, B. I. Sang, J. Hong, K. J. Yoon, J. W. Son, J. H. Lee, B. K. Kim and H. Kim, Catalytic Behavior of Metal Catalysts in High-Temperature RWGS Reaction: In Situ FT-IR Experiments and First-Principles Calculations, Sci. Rep., 2017, 1-10.

29 D. Tibiletti, A. Amieiro-Fonseca, R. Burch, Y. Chen, J. M. Fisher, A. Goguet, C. Hardacre, P. Hu and D. Thompsett, DFT and In Situ EXAFS Investigation of Gold/Ceria-Zirconia LowTemperature Water Gas Shift Catalysts: Identification of the Nature of the Active Form of Gold, J. Phys. Chem. B, 2005, 109(47), 22553-22559.

30 A. Goguet, R. Burch, Y. Chen, C. Hardacre, P. Hu, R. W. Joyner, F. C. Meunier, B. S. Mun, D. Thompsett and D. Tibiletti, Deactivation Mechanism of a $\mathrm{Au} / \mathrm{CeZrO}_{4}$ Catalyst During a Low-Temperature Water Gas Shift Reaction, J. Phys. Chem. C, 2007, 111(45), 16927-16933.

31 J. S. Filhol and M. Neurock, Elucidation of the Electrochemical Activation of Water over Pd by First Principles, Angew. Chem., Int. Ed., 2006, 45(3), 403-406.

32 E. J. Peterson, A. T. DeLaRiva, S. Lin, R. S. Johnson, H. Guo, J. T. Miller, J. H. Kwak, C. H. F. Peden, B. Kiefer and L. F. Allard, et al., Low-Temperature Carbon Monoxide Oxidation Catalysed by Regenerable Atomically Dispersed Palladium on Alumina, Nat. Commun., 2014, 5, 1-11.

33 D. C. Grenoble, M. M. Estadt and D. F. Ollis, The Chemistry and Catalysis of the Water Gas Shift Reaction. 1. The Kinetics over Supported Metal Catalysts, J. Catal., 1981, 67(1), 90-102.

34 B. Castro-Dominguez, I. P. Mardilovich, L. C. Ma, R. Ma, A. G. Dixon, N. K. Kazantzis and Y. H. Ma, Integration of Methane Steam Reforming and Water Gas Shift Reaction in a Pd/Au/Pd-Based Catalytic Membrane Reactor for Process Intensification, Membranes, 2016, 6(3), 1-18.

35 I. P. Mardilovich, B. Castro-Dominguez, N. K. Kazantzis, T. Wu and Y. H. Ma, A Comprehensive Performance Assessment Study of Pilot-Scale Pd and Pd/Alloy Membranes under Extended Coal-Derived Syngas Atmosphere Testing, Int. J. Hydrogen Energy, 2015, 40(18), 6107-6117.

36 V. Mehar, M. Kim, M. Shipilin, M. Van Den Bossche, J. Gustafson, L. R. Merte, U. Hejral, H. Grönbeck, E. Lundgren and A. Asthagiri, et al., Understanding the Intrinsic Surface Reactivity of Single-Layer and Multilayer $\operatorname{PdO}(101)$ on $\operatorname{Pd}(100)$, ACS Catal., 2018, 8(9), 8553-8567.

37 C. J. Zhang and $\mathrm{P}$. $\mathrm{Hu}$, CO Oxidation on $\operatorname{Pd}(100)$ and Pd(111): A Comparative Study of Reaction Pathways and Reactivity at Low and Medium Coverages, J. Am. Chem. Soc., 2001, 123(6), 1166-1172. 
38 G. Kresse and J. Hafner, Ab Initio Molecular Dynamics for Liquid Metals, Phys. Rev. B: Condens. Matter Mater. Phys., 1993, 47(1), 558-561.

39 G. Kresse and J. Hafner, Ab Initio Molecular-Dynamics Simulation of the Liquid-Metal-Amorphous-Semiconductor Transition in Germanium, Phys. Rev. B: Condens. Matter Mater. Phys., 1994, 49(20), 14251-14269.

40 G. Kresse and J. Furthmüller, Efficient Iterative Schemes for $\mathrm{Ab}$ Initio Total-Energy Calculations Using a Plane-Wave Basis Set, Phys. Rev. B: Condens. Matter Mater. Phys., 1996, 54(16), 11169-11186.

41 P. E. Blöchl, Projector Augmented-Wave Method, Phys. Rev. B: Condens. Matter Mater. Phys., 1994, 50(24), 17953-17979.

42 J. P. Perdew and Y. Wang, Accurate and Simple Analytic Representation of the Electron-Gas Correlation Energy, Phys. Rev. B: Condens. Matter Mater. Phys., 1992, 45(23), 13244-13249.

43 J. P. Perdew, K. Burke and M. Ernzerhof, Generalized Gradient Approximation Made Simple, Phys. Rev. Lett., 1996, 77(18), 3865-3868.

44 A. Plauck, E. E. Stangland, J. A. Dumesic and M. Mavrikakis, Active Sites and Mechanisms for $\mathrm{H}_{2} \mathrm{O}_{2}$ Decomposition over Pd Catalysts, Proc. Natl. Acad. Sci. U. S. A., 2016, 113(14), E1973-E1982.

45 J. Xu, S. Guo, F. Hou, J. Li and L. Zhao, Methanol Oxidation on the PtPd(111) Alloy Surface: A Density Functional Theory Study, Int. J. Quantum Chem., 2017, 118(3), e25491.

46 G. Henkelman, B. P. Uberuaga and H. Jónsson, Climbing Image Nudged Elastic Band Method for Finding Saddle Points and Minimum Energy Paths, J. Chem. Phys., 2000, 113(22), 9901-9904.

47 G. Henkelman and H. Jónsson, Improved Tangent Estimate in the Nudged Elastic Band Method for Finding Minimum Energy Paths and Saddle Points, J. Chem. Phys., 2000, 113(22), 9901-9904.

48 G. Makov and M. Payne, Periodic Boundary Conditions in Ab Initio Calculations, Phys. Rev. B: Condens. Matter Mater. Phys., 1995, 51(7), 4014-4022.

49 J. Neugebauer and M. Scheffler, Adsorbate-Substrate and Adsorbate-Adsorbate Interactions of $\mathrm{Na}$ and $\mathrm{K}$ Adlayers on Al(111), Phys. Rev. B: Condens. Matter Mater. Phys., 1992, 46(24), 16067-16080.

50 W. Tang, E. Sanville and G. Henkelman, A Grid-Based Bader Analysis Algorithm without Lattice Bias, J. Phys.: Condens. Matter, 2009, 21(8), 084204.

51 S. Tsuzuki and H. P. Lüthi, Interaction Energies of van der Waals and Hydrogen Bonded Systems Calculated Using Density Functional Theory: Assessing the PW91 Model, J. Chem. Phys., 2001, 114(9), 3949-3957.

52 F. Ortmann, F. Bechstedt and W. G. Schmidt, Semiempirical van der Waals Correction to the Density Functional Description of Solids and Molecular Structures, Phys. Rev. B: Condens. Matter Mater. Phys., 2006, 73(20), 1-10.

53 M. Stamatakis and D. G. Vlachos, A Graph-Theoretical Kinetic Monte Carlo Framework for on-Lattice Chemical Kinetics, J. Chem. Phys., 2011, 134, 21.

54 J. Nielsen, M. D’Avezac, J. Hetherington and M. Stamatakis, Parallel Kinetic Monte Carlo Simulation Framework
Incorporating Accurate Models of Adsorbate Lateral Interactions, J. Chem. Phys., 2013, 139(22), 224706.

55 S. Piccinin and M. Stamatakis, CO Oxidation on $\operatorname{Pd}(111)$ : A First-Principles-Based Kinetic Monte Carlo Study, ACS Catal., 2014, 4(7), 2143-2152.

56 H. Prats, S. Posada-Pérez, J. A. Rodriguez, R. Sayós and F. Illas, Kinetic Monte Carlo Simulations Unveil Synergic Effects at Work on Bifunctional Catalysts, ACS Catal., 2019, 9(10), 9117-9126.

57 J. Nielsen, M. D’Avezac, J. Hetherington and M. Stamatakis, Parallel Kinetic Monte Carlo Simulation Framework Incorporating Accurate Models of Adsorbate Lateral Interactions, J. Chem. Phys., 2013, 139(22), 224706.

58 J. Y. Lim, J. McGregor, A. J. Sederman and J. S. Dennis, The Role of the Boudouard and Water-Gas Shift Reactions in the Methanation of $\mathrm{CO}$ or $\mathrm{CO}_{2}$ over $\mathrm{Ni} / \gamma-\mathrm{Al}_{2} \mathrm{O}_{3}$ Catalyst, Chem. Eng. Sci., 2016, 152, 754-766.

59 S. M. Rogers, C. R. A. Catlow, C. E. Chan-Thaw, A. Chutia, N. Jian, R. E. Palmer, M. Perdjon, A. Thetford, N. Dimitratos and A. Villa, et al., Tandem Site- and Size-Controlled Pd Nanoparticles for the Directed Hydrogenation of Furfural, ACS Catal., 2017, 7(4), 2266-2274.

60 W. Jones, P. P. Wells, E. K. Gibson, A. Chutia, I. P. Silverwood, C. R. A. Catlow and M. Bowker, Carbidisation of Pd Nanoparticles by Ethene Decomposition with Methane Production, ChemCatChem, 2019, 11(17), 4334-4339.

61 X. Y. Zhu, J. M. White, M. Wolf, E. Hasselbrink and G. Ertl, Photochemical Pathways of Water on $\operatorname{Pd}(111)$ at $6.4 \mathrm{eV}$, J. Phys. Chem., 1991, 95(21), 8393-8402.

62 A. Chutia, I. P. Silverwood, M. R. Farrow, D. O. Scanlon, P. P. Wells, M. Bowker, S. F. Parker and C. R. A. Catlow, Adsorption of Formate Species on $\mathrm{Cu}(h, k, l)$ Low Index Surfaces, Surf. Sci., 2016, 653, 45-54.

63 K. G. Papanikolaou, M. T. Darby and M. Stamatakis, Adlayer Structure and Lattice Size Effects on Catalytic Rates Predicted from KMC Simulations: NO Oxidation on $\mathrm{Pt}(111)$, J. Chem. Phys., 2018, 149(18), 184701.

64 A. Chatterjee and A. F. Voter, Accurate Acceleration of Kinetic Monte Carlo Simulations through the Modification of Rate Constants, J. Chem. Phys., 2010, 132(19), 194101.

65 M. Stamatakis and D. G. Vlachos, Equivalence of On-Lattice Stochastic Chemical Kinetics with the Well-Mixed Chemical Master Equation in the Limit of Fast Diffusion, Comput. Chem. Eng., 2011, 35(12), 2602-2610.

66 M. Núñez, T. Robie and D. G. Vlachos, Acceleration and Sensitivity Analysis of Lattice Kinetic Monte Carlo Simulations Using Parallel Processing and Rate Constant Rescaling, J. Chem. Phys., 2017, 147(16), 164103.

67 E. C. Dybeck, C. P. Plaisance and M. Neurock, Generalized Temporal Acceleration Scheme for Kinetic Monte Carlo Simulations of Surface Catalytic Processes by Scaling the Rates of Fast Reactions, J. Chem. Theory Comput., 2017, 13(4), 1525-1538.

68 T. Danielson, J. E. Sutton, C. Hin and A. Savara, SQERTSS: Dynamic Rank Based Throttling of Transition Probabilities in Kinetic Monte Carlo Simulations, Comput. Phys. Commun., 2017, 219, 149-163. 